\title{
A tribo Paniceae s.l. (Poaceae: Panicoideae) na Reserva Biológica de Mogi-Guaçu, SP, Brasil ${ }^{1}$
}

\author{
Rodrigo S. Rodrigues ${ }^{2,3}$ e Tarciso S. Filgueiras ${ }^{2}$
}

Recebido: 12.09.2013; aceito: 22.05.2014

\begin{abstract}
The tribe Paniceae s.l. (Poaceae: Panicoideae) in the Reserva Biológica de Mogi-Guaçu, São Paulo State, Brazil). The present study aimed to survey the species of Paniceae s.l. in the Reserva Biológica de Mogi-Guaçu (RBMG-SP), located between $22^{\circ} 11^{\prime}-18^{\prime} \mathrm{S}$ and $47^{\circ} 7^{\prime}-10^{\prime} \mathrm{W}$, in order to increase the knowledge of the grass flora of this conservation unit and of São Paulo State. The field trips were conducted between 2011 and 2012, comprising 11 expeditions. Specimens from the herbaria IAC, SP, SPF, and UEC were consulted. We confirmed the occurrence of 24 genera and 80 species for RBMG-SP. From these, 47 species are newly reported, 15 species are exotic, and 12 species are classified as threatened in the state. The richest genera are Paspalum (25 spp.), Panicum and Axonopus (7 spp. each), Digitaria (6 spp.), Ichnanthus and Urochloa (4 spp. each). Identification keys, comments, and images of the floral structures of each taxon are presented.
\end{abstract}

Keywords: Cerrado, conservation, floristic, grasses, taxonomy

RESUMO - (A tribo Paniceae s.l. (Poaceae: Panicoideae) na Reserva Biológica de Mogi-Guaçu, SP, Brasil). O presente estudo objetivou realizar o levantamento florístico das espécies da tribo Paniceae s.l. na Reserva Biológica de Mogi-Guaçu (RBMG-SP), localizada entre $22^{\circ} 11^{\prime}-18^{\prime} \mathrm{S}$ e $47^{\circ} 7^{\prime}-10^{\prime} \mathrm{W}$, com o intuito de contribuir para o conhecimento da flora agrostológica desta Unidade de Conservação e do Estado de São Paulo. As coletas foram realizadas entre 2011 e 2012, totalizando 11 expedições. Foram consultadas as coleções dos herbários IAC, SP, SPF e UEC. Foi confirmada a ocorrência de 24 gêneros e 80 espécies para a RBMG-SP. Destas, 47 espécies são referidas pela primeira vez, 15 são exóticas e 12 são classificadas como ameaçadas no Estado. Os gêneros mais ricos em espécies são Paspalum (25 spp.), Panicum e Axonopus ( 7 spp. cada), Digitaria (6 spp.), Ichnanthus e Urochloa (4 spp. cada). São apresentadas chaves de identificação, comentários e imagens das estruturas florais de cada táxon.

Palavras-chave: Cerrado, conservação, florística, gramíneas, taxonomia

\section{Introdução}

Poaceae constitui a quarta maior família botânica, sendo uma das famílias de maior destaque e importância dentre as monocotiledôneas, com cerca de 700 gêneros e 10.000-11.000 espécies distribuídas por todo o mundo (GPWG 2001, 2012). No Brasil a família está representada por 214 gêneros e 1.435 espécies (Filgueiras et al. 2014a). Constitui um dos componentes florísticos mais importantes e abundantes de ecossistemas florestais e savânicos (Shantz 1954, Viana \& Filgueiras 2008). Atualmente, Poaceae é classificada em 12 subfamílias (GPWG 2012), dentre elas Panicoideae, que apresenta 12 tribos (Soreng et al. 2011), incluindo Paniceae sensu stricto e Paspaleae. Apesar das evidências moleculares oferecerem suporte para esta circunscrição, ela ainda carece de sinapomorfias morfológicas (Sánchez-Ken \& Clark 2010, Morrone et al. 2012), por esta razão, neste trabalho optou-se pelo reconhecimento da tribo em seu sentido amplo, Paniceae sensu lato.

No Estado de São Paulo, Paniceae s.l. está representada por cerca de 35 gêneros e 230-250 espécies (Longhi-Wagner et al. 2001, 2011). No entanto, apesar de a flora agrostológica do Estado ser bastante estudada, vários trabalhos recentes, como os de Filgueiras \& Shirasuna (2009), Rodrigues \& Filgueiras (2013a) e Shirasuna \& Filgueiras (2013),

1. Parte da Dissertação de Mestrado do primeiro Autor

2. Instituto de Botânica, Programa de Pós-Graduação em Biodiversidade Vegetal e Meio Ambiente, Núcleo de Pesquisa Curadoria do Herbário SP, Caixa Postal 68041, CEP 04301-902, São Paulo, SP, Brasil

3. Autor para correspondência: rosaro_3588@yahoo.com.br 
têm contribuído substancialmente para aumentar o conhecimento desse componente florístico.

Este trabalho foi conduzido com o objetivo de levantar as espécies da tribo Paniceae s.l. na Reserva Biológica de Mogi-Guaçu (RBMG-SP), em São Paulo, e assim contribuir para o conhecimento da flora agrostológica dessa Unidade de Conservação e do Estado, bem como oferecer suporte para a identificação das espécies da tribo, a proteção de espécies nativas e a detecção de espécies invasoras.

\section{Material e métodos}

A Reserva Biológica de Mogi-Guaçu (RBMG-SP) está inserida dentro da área da Fazenda Campininha, localizada no noroeste do Estado de São Paulo, no município de Mogi-Guaçu, entre $22^{\circ} 10^{\prime}-18^{\prime} \mathrm{S}$ e $47^{\circ} 07^{\prime}$ $11^{\prime} \mathrm{W}$, com área total de 470 ha, compreendendo duas áreas disjuntas, a gleba A e a gleba B. A gleba A apresenta 343 ha e é atravessada pelo Córrego do Cortado, em praticamente toda a sua extensão; enquanto a gleba B apresenta 127 ha e é parcialmente atravessada pelo Córrego do Capitinguinha (GiudiceNeto 2010).

O clima caracteriza-se por inverno seco e verão chuvoso. A precipitação anual média e a temperatura anual média são da ordem de $1.335 \mathrm{~mm}$ e $20,5{ }^{\circ} \mathrm{C}$, respectivamente. O relevo é não acidentado, aplainado, com solos do tipo Latossolo Vermelho-Amarelo e textura arenosa ou argilosa. A vegetação típica é o cerradão, em diferentes estágios de regeneração, mas também são observados fragmentos de cerrado típico, matas de galeria, campos úmidos e brejosos, além de locais antropizados (Eiten 1963, Mantovani \& Martins 1993).

O levantamento florístico foi realizado durante os anos de 2011 e 2012, totalizando 11 expedições de coleta, com duração de três a cinco dias cada.
As coletas foram realizadas de forma a amostrar as diferentes fitofisionomias ocorrentes na área. Os espécimes coletados encontram-se depositados no Herbário SP e as duplicatas foram enviadas a vários herbários do Estado. Complementarmente, foram analisadas coleções dos Herbários IAC, SP, SPF e UEC.

A terminologia utilizada segue, em linhas gerais, Longhi-Wagner et al. (2001), porém termos como gluma inferior e superior, lema inferior e lema superior foram substituídos por gluma I e gluma II, lema I e lema II, respectivamente.

Para a classificação do status de conservação das espécies nativas, utilizou-se o conjunto de critérios adotados por Mamede et al. (2007). A informação sobre a distribuição global das espécies segue Zuloaga et al. (2003) e o Tropicos.org (2014). As imagens das estruturas morfológicas foram obtidas com o auxílio de câmera fotográfica acoplada a estereomicroscópio.

A abreviação dos nomes dos autores dos binômios e das obras originais (opus princeps) seguiu o IPNI (2014) e os acrônimos dos herbários seguem Thiers (2014).

\section{Resultados e Discussão}

Foi confirmada a ocorrência de 24 gêneros e 80 espécies de gramíneas pertencentes à tribo Paniceae s.l. na Reserva Biológica de Mogi-Guaçu (RBMG-SP). Do número total de gêneros, 14 representam novos registros para a RBMG-SP. Do número total de espécies, 47 correspondem a novas referências para a área, sendo 15 delas exóticas e 12 categorizadas com algum grau de ameaça no Estado de São Paulo. Os gêneros e espécies de Poaceae pertencentes à Paniceae s.l. ocorrentes na RBMG-SP podem ser identificados através das chaves que se seguem.

Chave para gêneros de Paniceae s.l. ocorrentes na Reserva Biológica de Mogi-Guaçu

1. Espiguetas com um conjunto de cerdas na base

2. Cerdas caducas com as espiguetas na maturidade 3. Cenchrus

2. Cerdas persistentes após a queda das espiguetas na maturidade 21. Setaria

1. Espiguetas sem um conjunto de cerdas na base

3. Espiguetas conspicuamente aristadas, ou pelo menos caudado-aristadas (então espiguetas híspido-escabras)

4. Inflorescência em panícula típica, subcontraída a laxa; gluma I reduzida, escamiforme; antécio superior membranáceo, hialino, menos consistente que as glumas e o lema I 12. Melinis

4. Inflorescência em ramos unilaterais; gluma I 1/2-3/4 do comprimento da espigueta; antécio superior enrijecido, não hialino, mais consistente que as glumas e o lema I 
5. Lígula ausente; espiguetas híspido-escabras 5. Echinochloa

5. Lígula presente, membranosa; espiguetas glabras ou com tricomas em direção ao ápice .... 13. Oplismenus

3. Espiguetas múticas ou com ápice acuminado a fortemente acuminado

6. Inflorescência em panícula típica, laxa, aberta, subcontraída, contraída, de ramos subverticilados ou espiciforme

7. Lema II com apêndices aliformes ou cicatrizes na base

9. Ichnanthus

7. Lema II sem apêndices aliformes ou cicatrizes na base

8. Plantas com aspecto bambusoide; espiguetas de inserção oblíqua nos pedicelos, enegrecidas na maturidade; antécio superior com um tufo de tricomas no ápice 10. Lasiacis

8. Plantas com aspecto não bambusoide; espiguetas de inserção ereta nos pedicelos (se algo oblíquas, então pálea I expandida na maturidade), esverdeadas, estramíneas, castanhas ou com máculas negras ou vináceas na maturidade, nunca enegrecidas; antécio superior sem tufo de tricomas no ápice

9. Gluma I ausente; antécio superior membranáceo a fracamente enrijecido com ápice e margens hialinos

1. Anthaenantia

9. Gluma I presente, às vezes reduzida; antécio superior enrijecido, ápice e margens não hialinos

10. Pálea I expandida na maturidade

11. Gluma I igual ou subigual à gluma II; antécio superior liso ou levemente papiloso, castanho-escuro na maturidade

14. Otachyrium

11. Gluma I menor que a gluma II; antécio superior papiloso, esverdeado ou estramíneo na maturidade 22. Steinchisma

10. Pálea I não expandida na maturidade

12. Lema II com ápice curtamente mucronado 16. Parodiophyllochloa

12. Lema II com ápice não mucronado

13. Gluma I igual ou subigual à gluma II

7. Homolepis

13. Gluma I menor que a gluma II

14. Panícula espiciforme; espiguetas congestas, turbinadas ou fusiformes, levemente gibosas 20. Sacciolepis

14. Panícula laxa a contraída; espiguetas congestas ou esparsas, globosas, ovadas, obovadas, elípticas ou lanceoladas, não gibosas

15. Antécio superior com tricomas bicelulares conspícuos esparsamente distribuídos 23. Trichanthecium

15. Antécio superior sem tricomas bicelulares, se tricomas presentes, então espiguetas concentradas no ápice dos ramos da inflorescência 16. Base da gluma I envolvendo a gluma II; antécio superior transversalmente rugoso 11. Megathyrsus

16. Base da gluma I não envolvendo a gluma II ou, se envolvendo, então antécio superior liso ou papiloso

17. Espiguetas 1,3-1,5(-1,6) mm de comprimento; lígula membranosa

17. Espiguetas 1,7-8,5 mm de comprimento; lígula membranosociliada, ciliada ou, se membranosa, espiguetas concentradas no ápice dos ramos da inflorescência 15. Panicum

6. Inflorescência em ramos unilaterais, terminais, alterno-dísticos, conjugados, subconjugados, digitados ou subverticilados

18. Antécio superior com cicatrizes na base do lema II 6. Echinolaena 18. Antécio superior sem cicatrizes na base do lema II

19. Gluma II provida de tricomas uncinados na maturidade 18. Pseudechinolaena

19. Gluma II não provida de tricomas uncinados na maturidade 
20. Gluma I ou ambas as glumas ausentes

21. Espiguetas com o dorso do lema II abaxial à ráquis

2. Axonopus

21. Espiguetas com o dorso do lema II adaxial à ráquis

22. Espiguetas lanceoladas a elípticas, biconvexas; lema II com margens

hialinas cobrindo total ou parcialmente a pálea II

4. Digitaria

22. Espiguetas ovadas a elípticas, plano-convexas, menos frequentemente

biconvexas; lema II sem margens hialinas cobrindo a pálea II

17. Paspalum

20. Gluma I presente

23. Antécio inferior neutro ou estaminado; pálea I sempre desenvolvida

24. Espiguetas plano-convexas

17. Paspalum

24. Espiguetas globosas

25. Lígula ausente; antécio superior liso ou apicalmente papiloso

19. Rugoloa

25. Lígula presente; antécio superior transversalmente ruguloso ou rugoso ..... 24. Urochloa

23. Antécio inferior neutro; pálea I ausente, raro rudimentar

26. Base da gluma I envolvendo a gluma II; antécio superior membranáceo a fracamente enrijecido, levemente escabro ou papiloso em direção ao ápice 8. Hymenachne

26. Base da gluma I não envolvendo a gluma II; antécio superior enrijecido, liso, papiloso ou rugoso, não escabro em direção ao ápice

27. Lema II com margens hialinas cobrindo a pálea II

4. Digitaria

27. Lema II sem margens hialinas cobrindo a pálea II

17. Paspalum

1. Anthaenantia P. Beauv., Ess. Agrostogr.: 48. 1812.

1.1. Anthaenantia lanata (Kunth) Benth., J. Linn. Soc., Bot. 19: 39. 1881.

Figura 1 a

Material selecionado: BRASIL. São PAULo: MogiGuaçu, Reserva Biológica de Mogi-Guaçu, 27-I-1981, M. Sugiyama \& W. Mantovani 112 (SP).

Distribuição: regiões tropicais e subtropicais das Américas Central e do Sul. No Brasil ocorre em todas as regiões, na Amazônia, no Cerrado e na Mata Atlântica (Arce \& Sano 2001b, Filgueiras et al. 2014g).

Conservação: preocupação menor. Nativa.

Nomes populares: capim-prateado, capim-zaranza, zaranza.

Foi coletada pela última vez na RBMG-SP há 31 anos. Novas coletas não foram realizadas durante este estudo. Vale ressaltar que o espécime J.R. Mattos \& N.F. Mattos 8458 (SP) apresenta gluma I desenvolvida em algumas espiguetas, o que não é descrito para o gênero, e pode concorrer para identificações errôneas.

2. Axonopus P. Beauv., Ess. Agrostogr.: 12. 1812.

Chave para identificação das espécies de Axonopus da Reserva Biológica de Mogi-Guaçu

1. Ráquis com tricomas tuberculados amarelados ou dourados conspícuos nas margens e no ápice dos pedicelos
2. Espiguetas levemente agudas inseridas em escavações da ráquis, 1,9-2 $\mathrm{mm}$ de comprimento; lema I 3-nervado; nós pilosos 2.3. A. chrysoblepharis

2. Espiguetas obtusas não inseridas em escavações da ráquis, $1,6-1,7 \mathrm{~mm}$ de comprimento; lema I 2-nervado; nós glabros 2.1. A. aureus

1. Ráquis e pedicelos glabros ou apenas escabros nas margens

3. Lâminas foliares com ápice obtuso 2.4. A. fissifolius

3. Lâminas foliares com ápice subagudo ou agudo

4. Inflorescência com 2-6 ramos alternos, subconjugados ou subdigitados

5. Plantas perenes; nós pilosos; lâminas foliares com colo não demarcado; espiguetas 2,5-3 mm de comprimento, com tricomas marginais conspícuos; lema I 2-nervado; lema II com tricomas apicais 2.5. A. marginatus

5. Plantas anuais; nós glabros; lâminas foliarescomcolodemarcado; espiguetas 1,3-1,7 mm de comprimento, com tricomas marginais inconspícuos; lema I 4-nervado, lema II glabro 2.2. A. capillaris

4. Inflorescência com 7-70 ramos alternos a subverticilados 
6. Bainhas foliares basais de aspecto caracteristicamente iridoide, conduplicadas, glabras ou apenas com fileira de tricomas sobre a nervura central, não fibrosas na senescência, margens ciliadas em direção ao ápice ..... 2.7. A. pressus

6. Bainhas foliares basais de aspecto não iridoide, convolutas, vilosas, fibrosas na senescência, margens glabras 2.6. A. pellitus

2.1. Axonopus aureus P. Beauv., Ess. Agrostogr.: 12. 1812.

Figura $1 \mathrm{~b}-\mathrm{c}$

Material selecionado: BRASIL. São Paulo: Mogi-Guaçu, Reserva Biológica de Mogi-Guaçu, 27-IV-1981, W. Mantovani \& M. Sugiyama 1822 (SP).

Distribuição: América Central até o sul do Brasil. No Brasil ocorre em todas as regiões, na Amazônia, na Caatinga, no Cerrado e na Mata Atlântica (Filgueiras \& Rodrigues 2014).

Conservação: quase ameaçada. Nativa.

Nomes populares: capim-dourado.

O último registro da espécie na RBMG-SP foi realizado há 31 anos. Novos indivíduos não foram localizados na área. O fato de a espécie não ter sido reencontrada é intrigante e deverá ser investigado no futuro, pois sugere a sua extinção local.

2.2. Axonopus capillaris (Lam.) Chase, Proc. Biol. Soc. Wash. 24: 133. 1911.

Figura $1 \mathrm{~d}$

Material selecionado: BRASIL. São Paulo: MogiGuaçu, Reserva Biológica de Mogi-Guaçu, 25-I-2012, R.S. Rodrigues \& C.V. Silva 282 (SP).

Distribuição: regiões tropicais das Américas Central e do Sul. No Brasil está presente em todas as regiões, na Amazônia, na Caatinga, no Cerrado e na Mata Atlântica (Filgueiras \& Rodrigues 2014).

Conservação: quase ameaçada. Nativa.

Nomes populares: não registrado.

Habita preferencialmente áreas de campos e bordas de áreas de cerrado. Na RBMG-SP foi coletada ao longo das trilhas, no cerradão e em bordas de mata da gleba A. Não foram localizados indivíduos na gleba B. Este é o primeiro registro da espécie para a Reserva.
2.3. Axonopus chrysoblepharis (Lag.) Chase, Proc. Biol. Soc. Wash. 24: 134. 1911.

Figura 1 e-f

Material selecionado: BRASIL. SÃo Paulo: MogiGuaçu, Reserva Biológica de Mogi-Guaçu, 23-V-1961, J.R. Mattos 8983 (SP).

Distribuição: América Central até o Paraguai e Brasil. No Brasil ocorre em todas as regiões, na Amazônia, na Caatinga, no Cerrado e na Mata Atlântica (Filgueiras \& Rodrigues 2014).

Conservação: em perigo. Foi coletada apenas uma vez na RBMG-SP, há mais de 50 anos. Nativa.

Nomes populares: capim-dourado.

Primeira citação da espécie para a RBMG-SP. $\mathrm{O}$ fato de a espécie não ter sido reencontrada na área é intrigante e deverá ser investigado no futuro, pois sugere a sua extinção local.

2.4. Axonopus fissifolius (Raddi) Kuhlm., Comm. Lin. Telegr., Bot. 67: 87. 1922.

Figura $1 \mathrm{~g}$

Material selecionado: BRASIL. SÃo PAUlo: MogiGuaçu, Reserva Biológica de Mogi-Guaçu, 5-III-1996, N.G. Moraes 11 (SP).

Distribuição: Américas, dos EUA até o Paraguai e sul do Brasil. No Brasil ocorre em todas as regiões, na Amazônia, na Caatinga, no Cerrado e na Mata Atlântica (Filgueiras \& Rodrigues 2014).

Conservação: preocupação menor. Esta espécie não foi reencontrada na área. Nativa.

Nomes populares: grama-tapete, grama-missioneira.

De acordo com informações contidas em rótulos de herbário, habita, preferencialmente, campos, gramados, locais arenosos e antropizados. $\mathrm{O}$ fato de a espécie não ter sido reencontrada na área é intrigante e deverá ser investigado no futuro.

2.5. Axonopus marginatus (Trin.) Chase ex Hitchc., Contr. U.S. Nat. Herb. 17: 226. 1913.

Figura $1 \mathrm{~h}$

Material selecionado: BRASIL. São Paulo: Mogi-Guaçu, Reserva Biológica de Mogi-Guaçu, 15-VI-2011, R.S. Rodrigues 124 (SP).

Distribuição: exclusiva da América do Sul. No Brasil ocorre em todas as regiões, na Caatinga, no Cerrado e na Mata Atlântica (Filgueiras \& Rodrigues 2014).

Conservação: quase ameaçada. Nativa. 

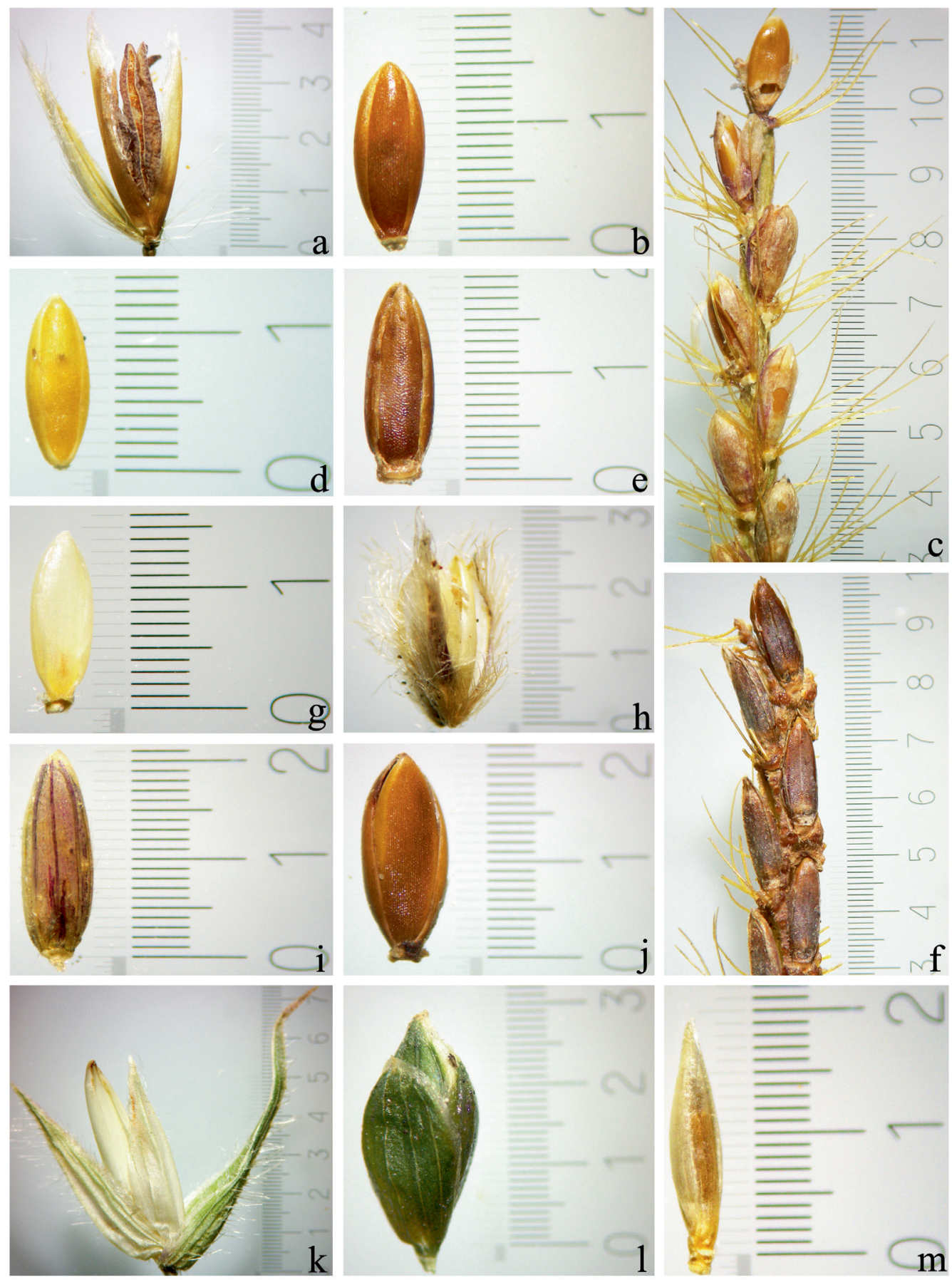

Figura 1. a. Anthaenantia lanata (Mantovani 180): espigueta, vista lateral, antécio inferior removido. b-c. Axonopus aureus (Mantovani 688): b. antécio superior, vista ventral; c. ápice do ramo da inflorescência. d. A. capillaris (Longhi-Wagner 3301): antécio superior, vista ventral. e-f. A. chrysoblepharis (Mattos 8983): e. antécio superior, vista ventral; f. ápice do ramo da inflorescência. g. A. fissifolius (Eiten 1954): antécio superior, vista ventral. h. A. marginatus (Oliveira 64): espigueta. i. A. pellitus (Rodrigues 237): espigueta. j. A. pressus (Rodrigues 208): antécio superior, vista ventral. k. Echinolaena inflexa (Rodrigues 150): espigueta. 1. Homolepis glutinosa [Rodrigues s.n. (SP440809)]: espigueta. m. Hymenachne pernambucensis (Leitão-Filho 12279): antécio superior, vista ventral. Escala em milímetros.

Figure 1. a. Anthaenantia lanata (Mantovani 180): spikelet, lateral view, lower anthecium removed. b-c. Axonopus aureus (Mantovani 688): b. upper anthecium, ventral view; c. apex of inflorescence branch. d. A. capillaris (Longhi-Wagner 3301): upper anthecium, ventral view. e-f. A. chrysoblepharis (Mattos 8983): e. upper anthecium, ventral view; f. apex of inflorescence branch. g. A. fissifolius (Eiten 1954): upper anthecium, ventral view. h. A. marginatus (Oliveira 64): spikelet. i. A. pellitus (Rodrigues 237): spikelet. j. A. pressus (Rodrigues 208): upper anthecium, ventral view. k. Echinolaena inflexa (Rodrigues 150): spikelet. 1. Homolepis glutinosa [Rodrigues s.n. (SP440809)]: spikelet. m. Hymenachne pernambucensis (Leitão-Filho 12279): upper anthecium, ventral view. Scale in millimeters. 
Nomes populares: capim-mole.

Na RBMG-SP apenas um indivíduo foi coletado na gleba A. Não foram localizados indivíduos na gleba B.

2.6. Axonopus pellitus (Nees ex Trin.) Hitchc. \& Chase, Contr. U.S. Natl. Herb. 18: 301. 1917. Figura $1 \mathrm{i}$

Material selecionado: BRASIL. São Paulo: Mogi-Guaçu, Reserva Biológica de Mogi-Guaçu, 20-XII-2011, R.S. Rodrigues \& C.V. Silva 237 (SP).

Distribuição: exclusiva da América do Sul. No Brasil ocorre em todas as regiões, na Caatinga, no Cerrado e na Mata Atlântica (Valls et al. 2001, Giraldo-Cañas 2010, Filgueiras \& Rodrigues 2014).

Conservação: quase ameaçada. Nativa.

Nomes populares: não registrado.

Registrada apenas na gleba A, onde forma densas touceiras. Não foram localizados indivíduos na gleba B. Apresenta grande variação morfológica, tanto nas estruturas vegetativas quanto reprodutivas.

\subsection{Axonopus pressus (Nees ex Steud.) Parodi, Notas} Mus. La Plata, Bot. 3: 23. 1938.

Figura $1 \mathrm{j}$

Material selecionado: BRASIL. São Paulo: MogiGuaçu, Reserva Biológica de Mogi-Guaçu, 25-X-2011, R.S. Rodrigues 208 (SP).

Distribuição: exclusiva da América do Sul. No Brasil ocorre em todas as regiões, na Amazônia, na Caatinga, no Cerrado e na Mata Atlântica (Valls et al. 2001, Filgueiras \& Rodrigues 2014).

Conservação: preocupação menor. Nativa.

Nomes populares: não registrado.

Primeira citação desta espécie para a RBMG-SP. Ocorre com frequência em áreas do entorno e margens de vias que cortam a RBMG-SP, na gleba A. Não foram localizados indivíduos na gleba $\mathrm{B}$.

3. Cenchrus L., Sp. Pl. 2: 1049. 1753.

Chave para identificação das espécies de Cenchrus da Reserva Biológica de Mogi-Guaçu

1. Plantas anuais, 50-73 cm de comprimento; inflorescência espinescente, não plumosa 3.1. C. echinatus

1. Plantas perenes, $200-600 \mathrm{~cm}$ de comprimento; inflorescência não espinescente, plumosa 3.2. C. purpureus
3.1. Cenchrus echinatus L., Sp. Pl. 2: 1050. 1753. Figura $4 \mathrm{a}-\mathrm{b}$

Material selecionado: BRASIL. SÃo Paulo: MogiGuaçu, Reserva Biológica de Mogi-Guaçu, 10-XII1959, G. Eiten 1553 (NY, SP).

Distribuição: pantropical. No Brasil ocorre em todas as regiões, na Amazônia, na Caatinga, no Cerrado, na Mata Atlântica e no Pantanal (Filgueiras 2014a).

Conservação: preocupação menor. Nativa.

Nomes populares: carrapicho, carrapicho-amoroso, carrapicho-de-cigano, hati-espinhoso, roseta, capimroseta, timbete.

Considerada boa forrageira quando jovem, é invasora agressiva de culturas, extremamente nociva quando presente em campos de produção de sementes de arroz (Filgueiras 1984). Existe apenas uma coleta desta espécie para a RBMG-SP, realizada há 54 anos, entretanto, é a primeira vez que este táxon é referido para a Reserva.

3.2. Cenchrus purpureus (Schumach.) Morrone, Ann.

Bot. (Oxford) 106: 129. 2010.

Figura 4 c-d

Material selecionado: BRASIL. São Paulo: Mogi-Guaçu, Reserva Biológica de Mogi-Guaçu, 21-VIII-2012, R.S. Rodrigues \& M. Pastore 303 (SP).

Distribuição: trópicos e subtrópicos. Na América ocorre desde os Estados Unidos até a Argentina. No Brasil ocorre em todas as regiões, na Amazônia, na Caatinga, no Cerrado e na Mata Atlântica (Filgueiras 2014a).

Conservação: preocupação menor. Exótica.

Nomes populares: capim-napiê, capim-napier, capimelefante, capim-rabo-de-raposa, napiê.

Encontrada em áreas de cultivo, bordas de estradas, matas perturbadas e margens de córregos, em solos secos ou brejosos (Boldrini 2001). Apresenta alto poder de dispersão e é muito agressiva, podendo impedir a regeneração da vegetação nativa em áreas alteradas. Por essa razão, é espécie alvo nos esforços de controle das invasoras exóticas do Estado de São Paulo. Na RBMG-SP, uma grande população foi encontrada na gleba A. Sua ocorrência está provavelmente associada à intensa atividade agrícola desenvolvida nas propriedades vizinhas e ao intenso tráfego de veículos nas estradas que cortam a Reserva. 
É citada na literatura sob o nome Pennisetum purpureum Schumach. (Boldrini 2001).

4. Digitaria Haller, Hist. Stirp. Helv. 2: 244. 1768.

Chave para identificação das espécies de Digitaria da Reserva Biológica de Mogi-Guaçu

1. Plantas cespitosas, eretas

2. Bainhas vilosas, fibrosas quando velhas; gluma II 1/2-3/4 do comprimento da espigueta 4.5. D. neesiana

2. Bainhas glabras ou pilosas na base, não fibrosas quando velhas; gluma II de comprimento subigual à espigueta ... 4.4.D. insularis

1. Plantas cespitoso-decumbentes, decumbentes ou estoloníferas

3. Espiguetas com pedicelos de comprimento subigual, 1-1,5 mm; antécio superior com ápice agudo ......................... 4.6. D. violascens

3. Espiguetas com pedicelos de comprimento conspicuamente desigual, 2,3-3 mm; antécio superior com ápice acuminado 4. Plantas perenes; bainha glabra ou com tricomas não tuberculados de até $1,5 \mathrm{~mm}$ de comprimento; ráquis glabra ... 4.2.D. eriantha

4. Plantas anuais; bainha tuberculadopilosa, tricomas com $3,5-7 \mathrm{~mm}$ de comprimento; ráquis glabra ou com tricomas longos, esparsos, na base dos pedicelos de algumas espiguetas

5. Espiguetas (2,7-)3-3,5 mm de comprimento; cariopse $1,8-2 \mathrm{~mm}$ de comprimento 4.1.D. ciliaris

5. Espiguetas 2-2,6 mm de comprimento; cariopse 1,4-1,6 $\mathrm{mm}$ de comprimento 4.3. D. horizontalis

4.1. Digitaria ciliaris (Retz.) Koeler, Descr. Gram.: 27. 1802.

Figura 4 e-f

Material selecionado: BRASIL. São Paulo: Mogi-Guaçu, Reserva Biológica de Mogi-Guaçu, 14-IX-2011, R.S. Rodrigues 176 (SP).

Distribuição: América, oeste e sul da África, China, Austrália e na Oceania. No Brasil apresenta ampla distribuição, estando presente em todas as regiões e biomas (Canto-Dorow 2014)

Conservação: preocupação menor. Exótica.

Nomes populares: capim-colchão, milhã ou capimmilhã.
Esta é a primeira vez que a espécie é citada para a RBMG-SP. Ocorre associada às demais espécies ruderais nas bordas das matas da gleba A. Sua presença está associada, provavelmente, à intensa atividade agrícola desenvolvida nas propriedades vizinhas.

4.2. Digitaria eriantha Steud., Flora 12(2): 468. 1829. Figura 4 g-h

Material selecionado: BRASIL. SÃo PAUlo: MogiGuaçu, Reserva Biológica de Mogi-Guaçu, 26-X-2011, R.S. Rodrigues 231 (SP).

Distribuição: regiões tropicais e subtropicais da América, África do Sul e na Austrália. No Brasil restringe-se as regiões Nordeste, Centro-Oeste, Sudeste e Sul; no Cerrado, na Mata Atlântica, no Pampa e no Pantanal (Canto-Dorow 2014).

Conservação: preocupação menor. Exótica.

Nomes populares: capim-pangola.

Este é o primeiro registro da espécie para a RBMG-SP. Encontrada em borda de mata na gleba A. Sua ocorrência está associada, provavelmente, à intensa atividade agrícola desenvolvida nas propriedades vizinhas e ao intenso tráfego de veículos nas estradas que cortam a Reserva.

4.3. Digitaria horizontalis Willd., Enum. P1. 1: 92. 1809.

Figura 4 i-j

Material selecionado: BRASIL. São Paulo: Mogi-Guaçu, Reserva Biológica de Mogi-Guaçu, 21-VIII-2012, R.S. Rodrigues \& M. Pastore 304 (SP).

Distribuição: regiões tropicais da América e da Europa. Nas Américas ocorre desde os Estados Unidos até a Argentina. No Brasil ocorre em todas as regiões, na Amazônia, na Caatinga, no Cerrado, no Pantanal e na Mata Atlântica (Canto-Dorow 2014).

Conservação: preocupação menor. Exótica.

Nomes populares: capim-colchão, capim-de-roça.

Ocorre em locais alterados nos limites e adjacências da RBMG-SP, na gleba A.

4.4. Digitaria insularis (L.) Fedde, Bot. Jahresber.: 31: 778. 1904.

Figura 4 k-1

Material selecionado: BRASIL. São Paulo: Mogi-Guaçu, Reserva Biológica de Mogi-Guaçu, 19-VI-2012, R.S. Rodrigues \& C.V. Silva 294 (SP). 
Distribuição: Américas, dos Estados Unidos até a Argentina. No Brasil ocorre em todas as regiões e biomas (Canto-Dorow 2014).

Conservação: preocupação menor. Exótica.

Nomes populares: capim-amargoso, capimvassourinha.

Na RBMG-SP, ocorre ao longo de trilhas na gleba A e nas proximidades da sede. Sua ocorrência está associada, provavelmente, à intensa atividade agrícola desenvolvida nas propriedades vizinhas e ao intenso tráfego nas estradas que cortam a Reserva. Esta é a primeira citação da espécie para a RBMG-SP.

4.5. Digitaria neesiana Henrard, Blumea 1:99.1934. Figura 4 m-n

Material selecionado: BRASIL. São Paulo: Mogi-Guaçu, Reserva Biológica de Mogi-Guaçu, 17-IX-1980, W. Mantovani 1048 (SP).

Distribuição: endêmica da América do Sul. No Brasil ocorre nas regiões Centro-Oeste e Sudeste, somente no Cerrado (Canto-Dorow 2014).

Conservação: vulnerável. Nativa. Encontra-se na lista de espécies ameaçadas da flora do Brasil (Filgueiras et al. 2013) e na lista de espécies ameaçadas da IUCN (2013), sob a categoria em perigo (EN).

Nomes populares: capim-do-campo-limpo.

Poucos espécimes desta espécie estão representados nos herbários paulistas. Para a RBMG-SP, o único registro da ocorrência da espécie foi realizado há 34 anos.

4.6. Digitaria violascens Link, Hort. Berol. 1: 229. 1827.

Figura 4 o-p

Material selecionado: BRASIL. São PaUlo: Mogi-Guaçu, Reserva Biológica de Mogi-Guaçu, 14-IX-2011, R.S. Rodrigues 182 (SP).

Distribuição: Ásia, Oceania e regiões tropicais e subtropicais das Américas, desde os Estados Unidos até a Argentina. No Brasil ocorre nas regiões Norte, Nordeste, Sudeste e Sul; na Amazônia, na Caatinga, no Cerrado, na Mata Atlântica e no Pampa (CantoDorow 2014).

Conservação: preocupação menor. Exótica.

Nomes populares: capim-pangola, capim-colchão.

Habita áreas antropizadas e locais alterados. Esta é a primeira referência desta espécie para a RBMG-SP, onde foi registrada nas bordas de áreas de mata ou nos gramados junto à sede, na gleba $\mathrm{A}$.

5. Echinochloa P. Beauv., Ess. Agrostogr.: 53. 1812.

5.1. Echinochloa crus-galli (L.) P. Beauv., Ess. Agrostogr.: 53. 1812.

Figura $4 \mathrm{q}$

Material selecionado: BRASIL. São PAULo: MogiGuaçu, Reserva Biológica de Mogi-Guaçu, 8-V-1978, R. Monteiro 7686 (UEC).

Distribuição: regiões tropicais e subtropicais da América, da Ásia, da Europa e da África. No Brasil ocorre em todas as regiões e biomas (Shirasuna 2014a).

Conservação: preocupação menor. Exótica.

Nomes populares: capituva, capim-arroz, capimpavão, arroz-brabo ou rabo-de-burro.

Esta é a primeira referência desta espécie para a RBMG-SP, baseada em um registro realizado há 34 anos.

6. Echinolaena Desv., J. Bot. Agric. 1: 75. 1813.

6.1. Echinolaena inflexa (Poir.) Chase, Proc. Biol. Soc. Wash. 24: 117. 1911.

Figura $1 \mathrm{k}$

Material selecionado: BRASIL. São Paulo: Mogi-Guaçu, Reserva Biológica de Mogi-Guaçu, 15-IX-2011, R.S. Rodrigues 200 (SP).

Distribuição: exclusiva da América do Sul. No Brasil ocorre nas regiões Norte, Nordeste, Centro-Oeste e Sudeste; na Amazônia, na Caatinga, no Cerrado e na Mata Atlântica (Garcia-Santos \& Sano 2001, Filgueiras \& Oliveira 2014a).

Conservação: preocupação menor. Nativa.

Nomes populares: capim-flechinha, capim-flor.

Espécie bastante difundida na RBMG-SP, principalmente na gleba $\mathrm{A}$, onde ocorre ao longo das trilhas, em áreas abertas e em bordas de mata.

7. Homolepis Chase, Proc. Biol. Soc. Wash. 24: 146. 1911.

7.1. Homolepis glutinosa (Sw.) Zuloaga \& Soderstr., Smithsonian Contr. Bot. 59: 19. 1985.

Figura 11

Material selecionado: BRASIL. São Paulo: MogiGuaçu, Reserva Biológica de Mogi-Guaçu, 7-IV-2011, R.S. Rodrigues \& T.S. Filgueiras s.n. (SP440809). 
Distribuição: Américas, desde o México até a Argentina. No Brasil ocorre nas regiões Nordeste, Sudeste e Sul; no Cerrado e na Mata Atlântica (Shirasuna et al. 2014).

Conservação: preocupação menor. Nativa.

Nomes populares: papanduva, capim-papuã, papuãmelado, graminha-do-mato.

Este é o primeiro registro desta espécie para a RBMG-SP. Ocorre ao longo de trilhas, bordas e interior de matas na gleba $\mathrm{A}$.

8. Hymenachne P. Beauv., Ess. Agrostogr.: 48. 1812.

\subsection{Hymenachne pernambucensis (Spreng.)} Zuloaga, Amer. J. Bot. 90: 817. 2003.

Figura $1 \mathrm{~m}$

Material selecionado: BRASIL. São PAULo: MogiGuaçu, Reserva Biológica de Mogi-Guaçu, 6-II-1981, H. Leitão-Filho et al. 12279 (UEC).

Distribuição: endêmica da América do Sul. No Brasil ocorre nas regiões Nordeste, Centro-Oeste, Sudeste e Sul; na Caatinga, no Cerrado e na Mata Atlântica (Filgueiras \& Oliveira 2014b).

Conservação: Mamede et al. (2007) classificaram esta espécie como presumivelmente extinta no Estado. Essa classificação, entretanto, foi revista por Rodrigues \& Filgueiras (2013b), que sugeriram a sua inclusão sob a categoria de preocupação menor. Nativa.

Nomes populares: capim-gigante-das-baixadas, capim-de-pernambuco.

Esta é a primeira citação da espécie para a RBMG-SP, com base uma coleta realizada há 33 anos.

9. Ichnanthus P. Beauv., Ess. Agrostogr.: 56. 1812.

Chave para identificação das espécies de Ichnanthus da Reserva Biológica de Mogi-Guaçu

1. Antécio superior com apêndices aliformes na base 9.1. I. inconstans

1. Antécio superior com cicatrizes na base

2. Lígula ciliada; espiguetas curto-pediceladas congestas no ápice dos ramos com espigueta terminal longo-pedicelada ...... 9.3. I. procurrens

2. Lígula membranoso-ciliada; espiguetas uniformemente distribuídas ao longo dos ramos, todas curto-pediceladas
3. Gluma I aguda, geralmente menor que o comprimento do lema I; antécio superior rotado em $90^{\circ}$ sobre o eixo da ráquila 9.2. I. pallens

3. Gluma I longo-acuminada a subaristada, geralmente maior que o comprimento do lema I; antécio superior não rotado $90^{\circ}$ sobre o eixo da ráquila 9.4. I. tenuis

9.1. Ichnanthus inconstans (Trin. ex Nees) Döll, Fl. Bras. 2(2): 284. 1877.

Figura 2 a

Material selecionado: BRASIL. São Paulo: Mogi-Guaçu, Reserva Biológica de Mogi-Guaçu, 19-VI-2012, R.S. Rodrigues \& C.V. Silva 288 (SP).

Distribuição: endêmica da América do Sul. No Brasil ocorre nas regiões Nordeste, Centro-Oeste, Sudeste e Sul; na Caatinga, no Cerrado e na Mata Atlântica (Filgueiras et al. 2014e).

Conservação: preocupação menor. Nativa.

Nomes populares: não registrado.

Esta é a primeira referência dessa espécie para a RBMG-SP. Ocorre abundantemente na gleba A, ao longo de margens de trilhas, nas bordas e interior de mata e em áreas abertas. Não foram localizados indivíduos na gleba B.

9.2. Ichnanthus pallens (Sw.) Munro ex Benth., Fl. Hongk.: 414. 1861.

Figura $2 \mathrm{~b}$

Material selecionado: BRASIL. SÃo Paulo: MogiGuaçu, Reserva Biológica de Mogi-Guaçu, 24-I-2012, R.S. Rodrigues \& C.V. Silva 271 (SP).

Distribuição: Américas, desde os Estados Unidos até a Argentina, na África, Índia, China, Oceania e Austrália. No Brasil ocorre em todas as regiões, na Amazônia, na Caatinga, no Cerrado e na Mata Atlântica (Filgueiras et al. 2014e).

Conservação: preocupação menor. Nativa.

Nomes populares: não registrado.

Esta é a primeira referência da espécie para a RBMG-SP. Encontrada em ambas as glebas, no interior de matas, principalmente junto a corpos d'água. Eventualmente ocorre também nas margens de trilhas. 

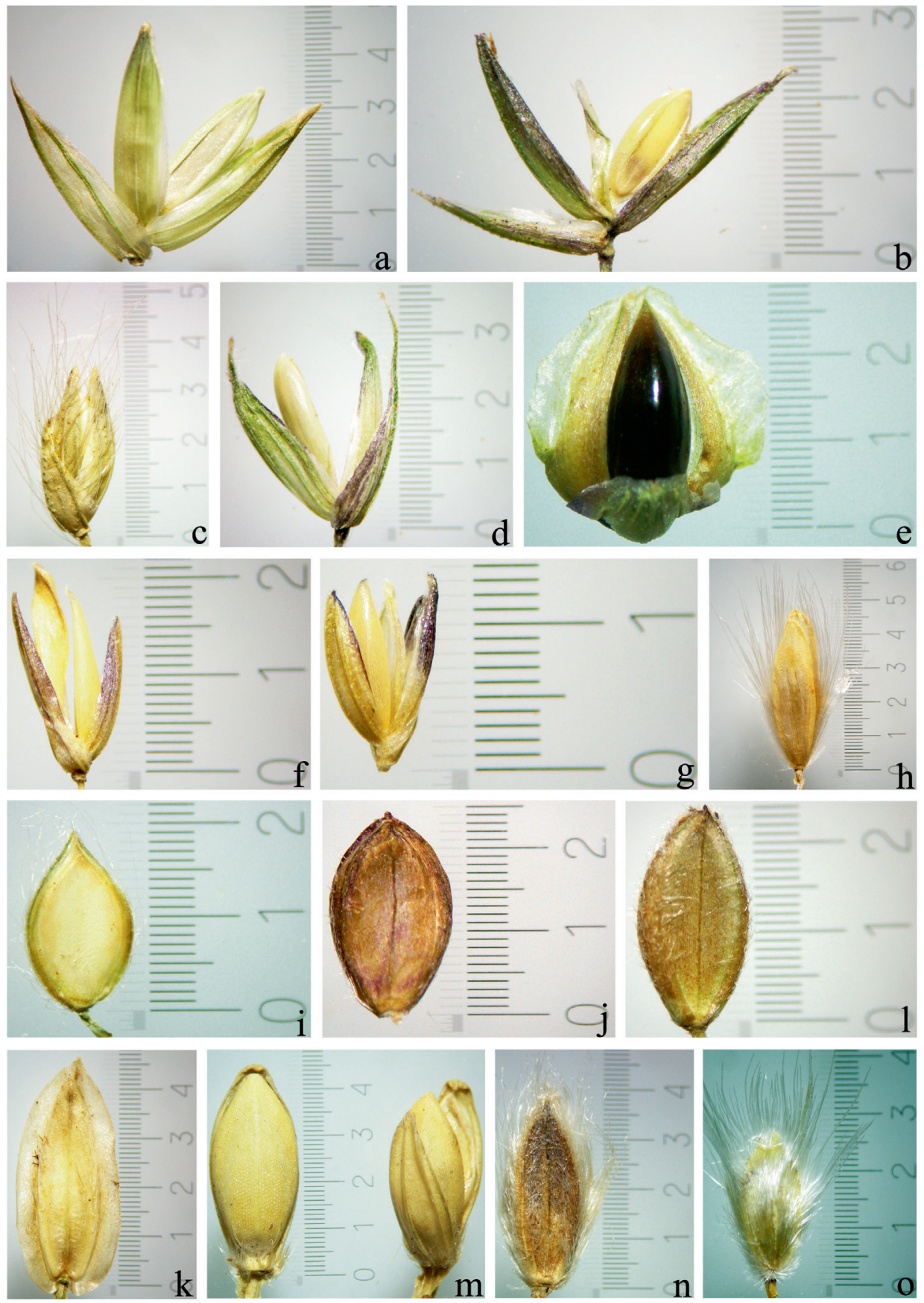

Figura 2. a. Ichnanthus inconstans (Rodrigues 284): espigueta. b. I. pallens (Rodrigues 271): espigueta. c. I. procurrens (Mantovani 374): espigueta. d. I. tenuis [Rodrigues s.n. (SP440803)]: espigueta. e. Otachyrium versicolor (Rodrigues 275): espigueta. f. Steinchisma decipiens (Eiten 2667): espigueta. g. S. laxum (Sendulsky 1119): espigueta. h. Paspalum carinatum (Eiten 1571): espigueta. i. P. conjugatum [Rodrigues S.n. (SP440805)]: espigueta. j. P. conspersum (Rodrigues 221): espigueta. k. P. cordatum (Rodrigues 260): espigueta. 1. P. coryphaeum (Rodrigues 240): espigueta. m. P. dedeccae (Kuhlmann 4254): espiguetas, gluma II ausente (esquerda) ou presente apenas na espigueta distal do ramo da inflorescência (direita). n. P. erianthum (Mattos 8500): espigueta. o. P. eucomum (Mantovani 522): espigueta. Escala em milímetros.

Figure 2. a. Ichnanthus inconstans (Rodrigues 284): spikelet. b. I. pallens (Rodrigues 271): spikelet. c. I. procurrens (Mantovani 374): spikelet. d. I. tenuis [Rodrigues s.n. (SP440803)]: spikelet. e. Otachyrium versicolor (Rodrigues 275): spikelet. f. Steinchisma decipiens (Eiten 2667): spikelet. g. S. laxum (Sendulsky 1119): spikelet. h. Paspalum carinatum (Eiten 1571): spikelet. i. P. conjugatum [Rodrigues s.n. (SP440805)]: spikelet. j. P. conspersum (Rodrigues 221): spikelet. k. P. cordatum (Rodrigues 260): spikelet. 1. P. coryphaeum (Rodrigues 240): spikelet. m. P. dedeccae (Kuhlmann 4254): spikelets, glume II absent (left) or developed only in the distal spikelet of the inflorescence branch (right). n. P. erianthum (Mattos 8500): spikelet. o. P. eucomum (Mantovani 522): spikelet. Scale in millimeters. 
9.3. Ichnanthus procurrens (Nees ex Trin.) Swallen, Phytologia 11: 149. 1964.

Figura $2 \mathrm{c}$

Material selecionado: BRASIL. São PAULo: MogiGuaçu, Reserva Biológica de Mogi-Guaçu, 26-I-1981, W. Mantovani 1535 (ICN, SP).

Distribuição: endêmica da América do Sul. No Brasil ocorre nas regiões Norte, Centro-Oeste, Sudeste e Sul; na Amazônia, na Caatinga, no Cerrado e na Mata Atlântica (Filgueiras et al. 2014e).

Conservação: preocupação menor. Nativa.

Nomes populares: não registrado.

O último registro da espécie na RBMG-SP foi realizado há 33 anos. Novos indivíduos não foram localizados durante os trabalhos de campo deste estudo.

9.4. Ichnanthus tenuis (J. Pres1 \& C. Presl) Hitchc. \& Chase, Contr. U.S. Natl. Herb. 18: 334. 1917.

Figura $2 \mathrm{~d}$

Material selecionado: BRASIL. São Paulo: MogiGuaçu, Reserva Biológica de Mogi-Guaçu, 7-IV-2011, R.S. Rodrigues \& T.S. Filgueiras s.n. (SP440803).

Distribuição: endêmica das Américas. No Brasil ocorre em todas as regiões, na Amazônia, na Caatinga, no Cerrado e na Mata Atlântica (Filgueiras et al. 2014e).

Conservação: preocupação menor. Nativa.

Nomes populares: não registrado.

Espécie aqui referida pela primeira vez para a RBMG-SP. Populações ocorrem às margens do Córrego do Cortado, na gleba A.

10. Lasiacis (Griseb.) Hitchc., Contr. U.S. Natl. Herb. 15: 16. 1910.

10.1. Lasiacis ligulata Hitchc. \& Chase, Contr. U.S. Natl. Herb. 18: 337. 1917.

Figura $4 \mathrm{r}$

Material selecionado: BRASIL. São Paulo: Mogi-Guaçu, Reserva Biológica de Mogi-Guaçu, 15-VI-2011, R.S. Rodrigues 125 (SP).

Distribuição: Américas, desde os Estados Unidos até a Argentina. No Brasil ocorre nas regiões Norte, Nordeste, Centro-Oeste e Sudeste; na Amazônia, na Caatinga, no Cerrado e na Mata Atlântica (Filgueiras \& Oliveira 2014c).
Conservação: preocupação menor. Nativa.

Nomes populares: taquari, taquari-mole.

Esta é a primeira vez que a espécie é referida para a RBMG-SP. Ocorre na gleba A, em diferentes pontos de área de mata e margens de trilhas.

11. Megathyrsus (Pilg.) B.K. Simon \& S.W.L. Jacobs, Austrobaileya 6(3): 572. 2003.

11.1. Megathyrsus maximus (Jacq.) B.K. Simon \& S.W.L. Jacobs, Austrobaileya 6(3): 572. 2003.

Figura $4 \mathrm{~s}$

Material selecionado: BRASIL. São Paulo: Mogi-Guaçu, Reserva Biológica de Mogi-Guaçu, 21-XII-2011, R.S. Rodrigues \& C.V. Silva 256 (SP).

Distribuição: África e Américas, desde os Estados Unidos até a Argentina. No Brasil ocorre em todas as regiões, na Amazônia, na Caatinga, no Cerrado, na Mata Atlântica e no Pantanal (Filgueiras 2014b).

Conservação: preocupação menor. Exótica.

Nomes populares: colonião, capim-colonião, capimguinea, capim-de-cavalo.

Espécie bastante difundida em ambas as glebas da RBMG-SP. Encontrada abundantemente nas bordas de matas, beira das rodovias e estradas que limitam e cortam a Reserva.

12. Melinis P. Beauv., Ess. Agrostogr.: 54. 1812.

Chave para identificação das espécies de Melinis da Reserva Biológica de Mogi-Guaçu

1. Bainhas e lâminas com tricomas glandulares; espiguetas glabras, 1,8-2,3 mm de comprimento; antécio inferior neutro, lema I com arista $5-14 \mathrm{~mm}$ de comprimento 12.1. M. minutiflora

1. Bainhas e lâminas com tricomas não glandulares; espiguetas densamente pilosas, 3,5-4,5 $\mathrm{mm}$ de comprimento; antécio inferior estaminado, lema I com arista 0,2-1,1 mm de comprimento 12.2. M. repens

12.1. Melinis minutiflora P. Beauv., Ess. Agrostogr.: 54. 1812.

Figura 5 a

Material selecionado: BRASIL. São Paulo: MogiGuaçu, Reserva Biológica de Mogi-Guaçu, 15-VI2011, R.S. Rodrigues 131 (SP). 
Distribuição: trópicos e América subtropical. No Brasil ocorre em todas as regiões, na Amazônia, na Caatinga, no Cerrado e na Mata Atlântica (Arce \& Sano 2001a, Filgueiras et al. 2014f).

Conservação: preocupação menor. Exótica.

Nomes populares: capim-gordura, capim-melado, capim-meloso, catingueiro, capim-catingueiro, capimroxo, capim-gordo, capim-cabelo-de-nego.

A ocorrência dessa espécie na RBMG-SP foi observada e documentada nas diferentes fisionomias, desde áreas abertas até total ou parcialmente sombreadas, em borda ou interior de mata. Indivíduos desta espécie formam densas populações em ambas as glebas.

12.2. Melinis repens (Willd.) Zizka, Biblioth. Bot. 138: 55. 1988.

Figura $5 \mathrm{~b}$

Material selecionado: BRASIL. São Paulo: Mogi-Guaçu, Reserva Biológica de Mogi-Guaçu, 14-IX-2011, R.S. Rodrigues 171 (SP).

Distribuição: pantropical e em algumas regiões subtropicais da América, África e Ásia, além da Austrália. No Brasil ocorre nas regiões Centro-Oeste, Sudeste e Sul; no Cerrado e na Mata Atlântica (Arce \& Sano 2001b, Filgueiras et al. 2014f).

Conservação: preocupação menor. Exótica.

Nomes populares: capim-gafanhoto, capim-de-lebre, capim-favorito, capim-mimoso, capim-natal.

Encontrada nas bordas de mata junto à rodovia, estradas e início de trilhas que cortam ambas as glebas, porém é mais abundante nas áreas da gleba $\mathrm{A}$.

13. Oplismenus P. Beauv., Fl. Oware 2: 14. 1810.

13.1. Oplismenus hirtellus (L.) P. Beauv., Ess. Agrostogr.: 54, 168, 170. 1812.

Figura $5 \mathrm{c}$

Material selecionado: BRASIL. São Paulo: Mogi-Guaçu, Reserva Biológica de Mogi-Guaçu, 20-XII-2011, R.S. Rodrigues \& C.V. Silva 242 (SP).

Distribuição: regiões tropicais da América, Ásia e Oceania. No Brasil ocorre nas regiões Norte, CentroOeste, Sudeste e Sul; na Amazônia, Caatinga, Cerrado e Mata Atlântica (Filgueiras et al. 2014b).

Conservação: preocupação menor. Nativa.
Nomes populares: não registrado.

Este é o primeiro registro da espécie para a RBMG-SP. Populações ocorrem no interior do chamado "Bosque do Pau-Brasil", junto à sede da Reserva; além disso, forma grupos esparsos ao longo de algumas trilhas de ambas as glebas.

14. Otachyrium Nees, Fl. Bras. Enum. Pl. 2(1): 273. 1829.

14.1. Otachyrium versicolor (Döll) Henrard, Blumea 4: 511. 1941.

Figura 2 e

Material selecionado: BRASIL. SÃo PaUlo: MogiGuaçu, Reserva Biológica de Mogi-Guaçu, 24-I-2012, R.S. Rodrigues \& C.V. Silva 275 (SP).

Distribuição: endêmica da América do Sul. No Brasil ocorre em todas as regiões, na Amazônia, no Cerrado e na Mata Atlântica (Sendulsky \& Soderstrom 1984, Filgueiras et al. 2014c).

Conservação: preocupação menor. Nativa.

Nomes populares: não registrado.

Este é o primeiro registro da espécie na RBMG-SP. Um único indivíduo foi localizado em área de campo seco arenoso na gleba A.

15. Panicum L., Sp. P1. 1: 55. 1753.

Chave para identificação das espécies de Panicum da Reserva Biológica de Mogi-Guaçu

1. Espiguetas concentradas no ápice dos ramos da inflorescência; antécio superior transversalmente ruguloso .......... 15.7. P. sellowii

1. Espiguetas regularmente distribuídas ao longo dos ramos da inflorescência; antécio superior liso ou papiloso

2. Antécio superior estipitado

3. Espiguetas 8-8,5 $\mathrm{mm}$ de comprimento 15.3. P. cervicatum

3. Espiguetas 2,4-3,5 $\mathrm{mm}$ de comprimento

4. Lígula ciliada; espiguetas $2,4-2,6 \mathrm{~mm}$ de comprimento; antécio inferior neutro 15.2. P. campestre

4. Lígula membranoso-ciliada; espiguetas 3-3,5 mm de comprimento; antécio inferior estaminado 15.6. P. rudgei

2. Antécio superior não estipitado 
5. Espiguetas 5,5-8 mm de comprimento; antécio superior com um tufo de tricomas na base 15.4. P. olyroides

5. Espiguetas 2,5-3,4 $\mathrm{mm}$ de comprimento; antécio superior sem tufo de tricomas na base

6. Gluma I aguda, maior que a metade do comprimento da espigueta 15.5. P. peladoense

6. Gluma I obtusa a subaguda, menor ou até a metade do comprimento da espigueta 15.1. P. aquaticum

15.1. Panicum aquaticum Poir., Encyc. Suppl. 4: 281. 1816

Figura $5 \mathrm{~d}$

Material selecionado: BRASIL. São PaUlo: MogiGuaçu, Reserva Biológica de Mogi-Guaçu,19-VI-2012, R.S. Rodrigues \& C.V. Silva 290 (SP).

Distribuição: endêmica da América tropical, desde o México até a Argentina. No Brasil distribui-se por todas as regiões e todos os biomas (Rodrigues 2014a).

Conservação: preocupação menor. Nativa.

Nomes populares: canarana, grama-do-banhado, grama-da-praia, grama-de-praia.

Antes da realização deste estudo, esta espécie somente havia sido amostrada na RBMG-SP há 52 anos. Indivíduos ocorrem parcialmente submersos nas margens do Córrego do Cortado, na gleba A, próximo à sede.

15.2. Panicum campestre Nees ex Trin., Gram. Panic.: 197. 1826.

Figura 5 e

Material selecionado: BRASIL. São PAulo: Mogi-Guaçu, Reserva Biológica de Mogi-Guaçu, 21-VIII-2012, R.S. Rodrigues \& M. Pastore 296 (SP).

Distribuição: endêmica do Brasil. Ocorre em todas as regiões, na Amazônia, na Caatinga, no Cerrado, na Mata Atlântica e no Pantanal (Rodrigues 2014a).

Conservação: preocupação menor. Nativa.

Nomes populares: colchão-pé-de-galinha.

Um único indivíduo foi localizado dentro da RBMG-SP durante a realização deste estudo. Entretanto, outros indivíduos foram observados em áreas antropizadas imediatamente adjacentes à Reserva.
15.3. Panicum cervicatum Chase, J. Wash. Acad. Sci. 32: 164. 1942.

Figura 5 f-g

Material selecionado: BRASIL. São Paulo: Mogi-Guaçu, Reserva Biológica de Mogi-Guaçu, 16-VI-2011, R.S. Rodrigues 157 (SP).

Distribuição: endêmica da América do Sul. Ocorre na Venezuela, na Bolívia, no Brasil e no Paraguai (Zuloaga et al. 2001). No Brasil ocorre em todas as regiões, na Amazônia, na Caatinga, no Cerrado, na Mata Atlântica e no Pantanal (Rodrigues 2014a).

Conservação: quase ameaçada. Nativa.

Nomes populares: não registrado.

Antes da realização deste estudo, esta espécie somente havia sido amostrada na RBMG-SP há 30 anos. Um único indivíduo foi encontrado vegetando em borda de mata na gleba A.

15.4. Panicum olyroides Kunth, Nov. Gen. Sp. 1: 102. 1816.

Figura 5 h-i

Distribuição: endêmica da América do Sul. No Brasil ocorre em todas as regiões e biomas (Rodrigues 2014a).

Conservação: preocupação menor. Nativa.

Nomes populares: capim-taquarinha.

A ocorrência desta espécie na RBMG-SP foi registrada pela última vez há 30 anos. No entanto, novos indivíduos não foram localizados durante os trabalhos de campo do presente estudo.

Zuloaga et al. (2001) e Rodrigues (2014a) reconheceram duas variedades para o Estado de São Paulo e para o Brasil, respectivamente. Ambas ocorrem na RBMG-SP.

Chave para identificação das variedades de Panicum olyroides da Reserva Biológica de Mogi-Guaçu

1. Bainhas e lâminas glabras ou glabrescentes; inflorescência com ráquis e pedicelos glabros 15.4.2. P. olyroides var. olyroides

1. Bainhas e lâminas densamente pilosas; inflorescência com ráquis e pedicelos pubescentes ou pilosos

15.4.1. P. olyroides var. hirsutum 
15.4.1. Panicum olyroides var. hirsutum Henrard, Meded. Rijks-Herb. 40: 52. 1921.

Material selecionado: BRASIL. São Paulo: MogiGuaçu, Reserva Biológica de Mogi-Guaçu, 5-IV-1966, W. Hoehne 6123 (SP).

Distribuição: além do Sudeste, do Centro-Oeste e do Sul do Brasil, ocorre no Paraguai e na Argentina (Zuloaga 1994, Rodrigues 2014a).

O último registro desta variedade para a RBMG-SP ocorreu há 46 anos.

\subsubsection{Panicum olyroides var. olyroides}

Material selecionado: BRASIL. São PaUlo: Mogi-Guaçu, Reserva Biológica de Mogi-Guaçu, 27-IV-1981, M. Sugiyama \& W. Mantovani 150 (SP).

Distribuição: ocorre em todas as regiões do Brasil, além da Venezuela, da Colômbia, da Bolívia, do Paraguai e da Argentina (Zuloaga 1994, Rodrigues 2014a).

O último registro desta variedade para a RBMGSP ocorreu há 30 anos.

15.5. Panicum peladoense Henrard, Blumea 4: 504. 1941.

Figura $5 \mathrm{j}$

Material selecionado: BRASIL. São Paulo: MogiGuaçu, Reserva Biológica de Mogi-Guaçu, 27-I-1981, M. Sugiyama \& W. Mantovani 40 (ICN, SP).

Distribuição: endêmica da América do Sul, ocorrendo no Brasil, na Bolívia, no Paraguai, no Uruguai e na Argentina. No Brasil ocorre em todas as regiões e biomas (Rodrigues 2014a).

Conservação: preocupação menor. Nativa.

Nomes populares: não registrado.

Embora plantas desta espécie tenham sido coletadas em 1960, 1980 e 1981, somente agora a espécie foi identificada e sua ocorrência na RBMGSP é registrada pela primeira vez. Nenhum indivíduo foi localizado em nenhuma das glebas durante os trabalhos de campo do presente estudo.

15.6. Panicum rudgei Roem. \& Schult., Syst. Veg. 2: 444.1817.

Figura 5 k-1

Material selecionado: BRASIL. São PAULO: MogiGuaçu, Reserva Biológica de Mogi-Guaçu, 24-I-2012, R.S. Rodrigues \& C.V. Silva 270 (SP).
Distribuição: Américas, desde o México até o Brasil, onde se distribui por praticamente todos os Estados, na Amazônia, na Caatinga, no Cerrado, na Mata Atlântica e no Pantanal (Rodrigues 2014a).

Conservação: preocupação menor. Nativa.

Nomes populares: penacho, navalhinha, capim-doroçado, capim-de-espinho.

Espécie amplamente disseminada na RBMG-SP. Ocorre abundantemente em áreas abertas da gleba A.

15.7. Panicum sellowii Nees, Fl. Bras. Enum. Pl. 2: 153. 1829.

Figura $5 \mathrm{~m}-\mathrm{n}$

Material selecionado: BRASIL. SÃo Paulo: MogiGuaçu, Reserva Biológica de Mogi-Guaçu, 24-I-2012, R.S. Rodrigues \& C.V. Silva 263 (SP).

Distribuição: Américas, desde o México até a Argentina. No Brasil ocorre em todas as regiões e biomas (Rodrigues 2014a).

Conservação: preocupação menor. Nativa.

Nomes populares: bambuzinho.

Esta é a primeira vez que a espécie é registrada para a RBMG-SP. Amplamente disseminada na área, ocorre em ambas as glebas, principalmente em bordas de mata e trilhas.

16. Parodiophyllochloa Zuloaga \& Morrone, Syst. Bot. 33: 69. 2008.

Chave para identificação das espécies de

Parodiophyllochloa da Reserva Biológica de Mogi-Guaçu

1. Plantas robustas; colmos lignificados, $150-350(-500) \mathrm{cm}$ de comprimento 16.3. P. penicillata

1. Plantas delgadas; colmos não lignificados, $10-150 \mathrm{~cm}$ de comprimento

2. Inflorescências com ramos de $3-10 \mathrm{~cm}$ de comprimento; espiguetas 3-3,4 mm de comprimento; gluma II e lema I 7nervados 16.1. P. ovulifera

2. Inflorescências com ramos de $0,5-3 \mathrm{~cm}$ de comprimento; espiguetas 2-2,3(-2,5) $\mathrm{mm}$ de comprimento; gluma II e lema I 5-nervados 16.2. P. pantricha 
16.1. Parodiophyllochloa ovulifera (Trin.) Zuloaga \& Morrone, Syst. Bot. 33: 73. 2008.

Figura 5 o-p

Material selecionado: BRASIL. São Paulo: Mogi-Guaçu, Reserva Biológica de Mogi-Guaçu, 15-VI-2011, R.S. Rodrigues 129 (SP).

Distribuição: Américas, desde o México até a Argentina. No Brasil ocorre nas regiões Nordeste, Centro-Oeste, Sudeste e Sul; no Cerrado, na Mata Atlântica, no Pampa e no Pantanal (Filgueiras et al. 2014d).

Conservação: preocupação menor. Nativa.

Nomes populares: não registrado.

Esta é a primeira vez que a espécie é registrada na RBMG-SP. Ocorre na gleba $\mathrm{A}$, às margens do Córrego do Cortado.

16.2. Parodiophyllochloa pantricha (Hack.) Zuloaga \& Morrone, Syst. Bot. 33: 73. 2008.

Figura 5 q-r

Material selecionado: BRASIL. São Paulo: MogiGuaçu, Reserva Biológica de Mogi-Guaçu, 26-X-2011, R.S. Rodrigues 219 (SP).

Distribuição: desde Honduras e Panamá até a Argentina. No Brasil ocorre nas regiões Nordeste, Centro-Oeste, Sudeste e Sul; no Cerrado, na Mata Atlântica, no Pampa e no Pantanal (Filgueiras et al. 2014d).

Conservação: preocupação menor. Nativa.
Nomes populares: não registrado.

Esta é a primeira vez que a espécie é registrada na RBMG-SP. Ocorre na gleba A, em locais de solo arenoso ou úmido, parcialmente sombreados, associada às bordas de mata e trilhas.

16.3. Parodiophyllochloa penicillata (Nees ex Trin.) Zuloaga \& Morrone, Syst. Bot. 33: 74. 2008.

Figura 6 a-b

Material selecionado: BRASIL. São Paulo: MogiGuaçu, Reserva Biológica de Mogi-Guaçu, 24-I-2012, R.S. Rodrigues \& C.V. Silva 264 (SP).

Distribuição: endêmica do Brasil. Ocorre nas regiões Nordeste, Centro-Oeste e Sudeste, no Cerrado e na Mata Atlântica (Filgueiras et al. 2014d).

Conservação: até o momento, as únicas populações desta espécie conhecidas no Estado de São Paulo estão localizadas na área da RBMG-SP. Rodrigues \& Filgueiras (2013a) sugeriram a classificação desta espécie como vulnerável no Estado de São Paulo.

Nomes populares: não registrado.

Este é o primeiro registro da espécie na RBMG$\mathrm{SP}$, onde ocorre em ambas as glebas. Na gleba A, ocorre em borda de mata na porção oeste da Reserva, junto ao Ribeirão das Araras. Na gleba B, ocorre nas porções de mata junto às margens do Córrego do Capitinguinha.

17. Paspalum L., Syst. Nat., ed. 10. 2: 855. 1759.

Chave para identificação das espécies de Paspalum da Reserva Biológica de Mogi-Guaçu

1. Glumas I e II ausentes, às vezes a gluma II presente somente na última espigueta do ápice dos ramos da inflorescência

2. Espiguetas binadas, 1,7-2 mm de comprimento; gluma II ausente em todas as espiguetas dos ramos da inflorescência

3. Pedicelos escabros; espiguetas plano-convexas a côncavo-convexas, falciformes; lema II 5-nervado, nervuras proeminentes 17.12. P. malacophyllum

3. Pedicelos com tricomas longos e conspícuos, dourados ou castanhos; espiguetas planoconvexas, não falciformes; lema II 3-nervado, nervuras inconspícuas .... 17.9. P. gardnerianum

2. Espiguetas solitárias, 4-5 mm de comprimento; gluma II ausente ou presente somente na última espigueta dos ramos da inflorescência 17.6. P. dedeccae

1. Glumas I e II presentes ou somente a gluma II presente

4. Gluma II e lema I com margens aladas

5. Inflorescência com 2-(4) ramos, subconjugados, raro alternos; lema I de base cordada; antécio superior com tricomas de comprimento uniforme nas margens e no ápice ...... 17.18. P. pectinatum

5. Inflorescência com 3-9 ramos, alternos; lema I de base não cordada; antécio superior com tricomas de comprimento desigual, curtos nas margens e longos em direção ao ápice 17.4. P. cordatum

4. Gluma II e lema I com margens não aladas 
6. Inflorescência com dois ramos unilaterais, conjugados ou subconjugados, às vezes com um terceiro ramo abaixo do par conjugado

7. Espiguetas com tricomas glandulares, subglobosos

17.14. P. multicaule

7. Espiguetas glabras ou com tricomas tectores

8. Espiguetas com gluma II e lema I cartáceos, papilosos, geralmente maculados, máculas castanhas ou vináceas 17.11. P. maculosum

8. Espiguetas com gluma II e lema I membranáceos, não papilosos, não maculados

9. Antécio superior com um tufo de tricomas apicais 17.1. P. carinatum

9. Antécio superior glabro

10.Plantas com rizomas evidentes acima do solo; espiguetas 3-3,5 mm de comprimento, glabras 17.15.P. notatum

10.Plantas com rizomas não evidentes acima do solo; espiguetas $1,4-2,8 \mathrm{~mm}$ de comprimento, pilosas

11. Plantas cespitosas, eretas; ráquis alada; espiguetas densamente pilosas no dorso e nas margens

17.8. P. еисотит

11. Plantas decumbentes; ráquis não alada; espiguetas com dorso glabro e tricomas longos nas margens 17.2. P. conjugatum

6. Inflorescência com um único ramo unilateral terminal ou 2-muitos ramos, alternos

12. Espiguetas solitárias 17.1. P. carinatum

12. Espiguetas binadas

13. Antécio superior castanho a castanho-escuro na maturidade

14.Lema I frequentemente plicado, margens esverdeadas e uma porção central subhialina, evidenciando a cor escura do antécio superior, ou às vezes a porção central levemente acinzentada

15. Gluma II e lema I conspicuamente variegados 17.10. P. geminiflorum

15. Gluma II e lema I não variegados

16. Espiguetas 2,5-3,1 mm de comprimento; cariopse ca. $1,8 \times 1,3 \mathrm{~mm}$ 17.20. P. plicatulum

16. Espiguetas 3,6-4 mm de comprimento; cariopse ca. 2,5 × 0,5-0,6 mm 17.22. P. rojasii

14. Lema I não plicado, cor uniforme

17. Espiguetas elípticas

17.3. P. conspersum

17. Espiguetas obovadas 17.24. P. virgatum

13. Antécio superior esverdeado a estramíneo na maturidade

18. Inflorescência com 1-(3) ramo(s) unilateral(is)

19. Espiguetas pilosas, tricomas longos nas margens da gluma II e lema I ..... 17.21. P. polyphyllum

19. Espiguetas glabras

20. Plantas eretas ou decumbentes; ramo da inflorescência 6-17 cm de comprimento; gluma I e pálea I presentes 17.19. P. pilosum

20. Plantas estoloníferas; ramo da inflorescência $2,5-4,5 \mathrm{~cm}$ de comprimento; gluma I e pálea I ausentes, ocasionalmente gluma I presente em algumas espiguetas 17.16. P. nutans

18. Inflorescência com (3-)4-muitos ramos unilaterais

21. Espiguetas glabras a glabrescentes, tricomas inconspícuos

22. Espiguetas elíptico-obovadas a obovadas; lema I com uma porção central sub-hialina, evidenciando a cor estramínea do antécio superior; gluma II 3-nervada 17.25. Paspalum sp. 1

22. Espiguetas oblongo-elípticas; lema I com cor uniforme; antécio superior esverdeado a levemente estramíneo; gluma II (3-)5-nervada 17.13. P. mandiocanum

21. Espiguetas conspicuamente pilosas

23. Espiguetas $1,2-1,4 \mathrm{~mm}$ de comprimento 17.17. P. paniculatum

23. Espiguetas $2-4,6 \mathrm{~mm}$ de comprimento 
24. Espiguetas largo-elípticas a levemente ovais 17.23. P. urvillei

24.Espiguetas elípticas a lanceoladas

25. Antécio superior glabro 17.5. P. coryphaeum

25. Antécio superior pubescente 17.7. P. erianthum

17.1. Paspalum carinatum Humb. \& Bonpl. ex Flüggé, Gram. Monogr., Paspalum: 65. 1810.

Figura $2 \mathrm{~h}$

Material selecionado: BRASIL. São Paulo: Mogi-Guaçu, Reserva Biológica de Mogi-Guaçu, 10-XII-1959, G. Eiten 1571 (NY, SP).

Distribuição: América Central e América do Sul, desde a Nicarágua até o Brasil. No Brasil ocorre em todas as regiões, na Amazônia, na Caatinga, no Cerrado, na Mata Atlântica e no Pantanal (Valls \& Oliveira 2014).

Conservação: preocupação menor. Nativa.

Nomes populares: grama-das-pedras.

O último registro da espécie na RBMG-SP ocorreu há 53 anos. Novos indivíduos não foram localizados durante os trabalhos de campo deste estudo.

17.2. Paspalum conjugatum P.J. Bergius, Acta Helv. Phys.-Math. 7: 129. 1772.

Figura $2 \mathrm{i}$

Material selecionado: BRASIL. São PaUlo: Mogi-Guaçu, Reserva Biológica de Mogi-Guaçu, 21-XII-2011, R.S. Rodrigues \& C.V. Silva 253 (SP).

Distribuição: regiões tropicais da América, África, Ásia e na Austrália. No Brasil ocorre em todas as regiões e biomas (Valls \& Oliveira 2014).

Conservação: preocupação menor. Nativa.

Nomes populares: capim-gordo.

Esta é a primeira vez que a espécie é registrada para a RBMG-SP. Ocorre em bordas de mata e trilhas de ambas as glebas, além de locais sombreados ao longo do Córrego do Cortado.

17.3. Paspalum conspersum Schrad., Mant. 2: 174. 1824.

Figura $2 \mathrm{j}$

Material selecionado: BRASIL. São PaUlo: MogiGuaçu, Reserva Biológica de Mogi-Guaçu, 26-X-2011, R.S. Rodrigues 221 (SP).

Distribuição: Américas, desde os Estados Unidos até a Argentina. No Brasil ocorre em todas as regiões, na Amazônia, no Cerrado, na Mata Atlântica e no Pantanal (Valls \& Oliveira 2014).
Conservação: preocupação menor. Nativa.

Nomes populares: capim-milhã, milhã, milhã-branco, capim-de-mula, capim-batatais.

Esta é a primeira vez que a espécie é registrada para a RBMG-SP. O único indivíduo encontrado crescia em local alterado em borda de mata da gleba A.

17.4. Paspalum cordatum Hack., Dusén, Ark. Bot. 9: 5. 1910.

Figura $2 \mathrm{k}$

Material selecionado: BRASIL. São Paulo: Mogi-Guaçu, Reserva Biológica de Mogi-Guaçu, 21-XII-2011, R.S. Rodrigues \& C.V. Silva 260 (SP).

Distribuição: endêmica da América do Sul. Ocorre na Colômbia e no Brasil, onde se distribui pelas regiões Norte, Centro-Oeste, Sudeste e Sul; na Amazônia, no Cerrado e na Mata Atlântica (Denham et al. 2002, Valls \& Oliveira 2014).

Conservação: preocupação menor. Nativa.

Nomes populares: não registrado.

O último registro desta espécie na RBMG-SP havia sido realizado há mais de 50 anos. Ocorre na gleba A, em áreas mais abertas. Não foram localizados indivíduos na gleba B.

17.5. Paspalum coryphaeum Trin., Gram. Panic.: 114. 1826.

Figura 21

Material selecionado: BRASIL. São Paulo: Mogi-Guaçu, Reserva Biológica de Mogi-Guaçu, 20-XII-2012, R.S. Rodrigues \& C.V. Silva 240 (SP).

Distribuição: Américas, desde os Estados Unidos até a Argentina. No Brasil ocorre nas regiões Norte, Nordeste, Centro-Oeste e Sudeste; na Amazônia, no Cerrado, na Mata Atlântica e no Pantanal (Valls \& Oliveira 2014).

Conservação: preocupação menor. Nativa.

Nomes populares: não registrado.

Esta é a primeira vez que a espécie é referida para a RBMG-SP, apesar de existirem coletas realizadas há mais de 50 anos no local. Ocorre em áreas abertas e bordas de mata da gleba $\mathrm{A}$. 
17.6. Paspalum dedeccae Quarín., Bonplandia (Corrientes) 3(14): 206. 1975.

Figura $2 \mathrm{~m}$

Material selecionado: BRASIL. São Paulo: MogiGuaçu, Reserva Biológica de Mogi-Guaçu, 30-X-1957, M. Kuhlmann 4254 (SP).

Distribuição: endêmica da América do Sul. No Brasil ocorre nas regiões Centro-Oeste, Sudeste e Sul; no Cerrado e na Mata Atlântica (Valls \& Oliveira 2014).

Conservação: vulnerável. Nativa.

Nomes populares: não registrado.

Existem apenas quatro registros da ocorrência desta espécie no Estado, sendo um deles proveniente da RBMG-SP. Esta é, entretanto, a primeira vez que a espécie é formalmente referida para a Reserva. Não foram encontrados novos indivíduos durante os trabalhos de campo deste estudo.

17.7. Paspalum erianthum Nees ex Trin., Gram. Panic.: 121. 1826.

Figura $2 n$

Material selecionado: BRASIL. São Paulo: MogiGuaçu, Reserva Biológica de Mogi-Guaçu, 14-X-1980, W. Mantovani 1083 (SP).

Distribuição: Américas, desde o México até o Uruguai. No Brasil ocorre em todas as regiões, na Caatinga, no Cerrado e na Mata Atlântica (Valls \& Oliveira 2014).

Conservação: quase ameaçada. Nativa.

Nomes populares: macega-do-banhado.

$\mathrm{O}$ último registro da espécie para a RBMG-SP ocorreu há 34 anos. Não foram localizados novos indivíduos durante os trabalhos de campo deste estudo.

17.8. Paspalum eucomum Nees ex Trin., Sp. Gram. 1: t. 110.1828.

Figura 2 o

Material selecionado: BRASIL. São Paulo: MogiGuaçu, Reserva Biológica de Mogi-Guaçu, 9-IV-1980, W. Mantovani 689 (SP).

Distribuição: endêmica do Brasil. Ocorre nas regiões Centro-Oeste, Sudeste e Sul, exclusivamente em áreas de Cerrado (Denham et al. 2002, Valls \& Oliveira 2014).

Conservação: quase ameaçada. Nativa.

Nomes populares: não registrado.
O último registro da espécie para a RBMG-SP ocorreu há 34 anos. Esta é, entretanto, a primeira vez que a espécie é formalmente referida para a Reserva. Não foram localizados novos indivíduos durante os trabalhos de campo deste estudo.

17.9. Paspalum gardnerianum Nees, Hooker's J. Bot.

Kew Gard. Misc. 2: 103. 1850.

Figura 3 a

Material selecionado: BRASIL. São Paulo: Mogi-Guaçu, Reserva Biológica de Mogi-Guaçu, 19-VI-2012, R.S. Rodrigues \& C.V. Silva 295 (SP).

Distribuição: desde o Panamá até a Argentina. No Brasil ocorre em todas as regiões, na Amazônia, na Caatinga e no Cerrado (Valls \& Oliveira 2014).

Conservação: preocupação menor. Nativa.

Nomes populares: não registrado.

Encontra-se bem documentada na RBMG-SP, tendo sido coletada praticamente uma vez a cada dez anos. Ocorre na gleba A, em bordas de mata. Não foram localizados indivíduos na gleba $\mathrm{B}$.

17.10. Paspalum geminiflorum Steud., Syn. Pl. Glumac. 1: 25. 1853.

Figura 3 b

Material selecionado: BRASIL. São Paulo: MogiGuaçu, Reserva Biológica de Mogi-Guaçu, 24-V-1957, M. Kuhlmann 4197 (SP).

Distribuição: endêmica da América do Sul. No Brasil ocorre nas regiões Norte, Nordeste, Centro-Oeste e Sudeste; na Amazônia e no Cerrado (Valls \& Oliveira 2014).

Conservação: em perigo. Nativa.

Nomes populares: não registrado.

Existe apenas um registro desta espécie para a RBMG-SP, realizado há 57 anos. Esta é, entretanto, a primeira vez que a espécie é formalmente referida para a Reserva. Não foram localizados novos indivíduos durante os trabalhos de campo deste estudo.

17.11. Paspalum maculosum Trin., Gram. Panic.: 2: 98. 1826.

Figura $3 \mathrm{c}$

Material selecionado: BRASIL. São Paulo: Mogi-Guaçu, Reserva Biológica de Mogi-Guaçu, 16-XII-1959, G. Eiten 1607 (NY, SP). 

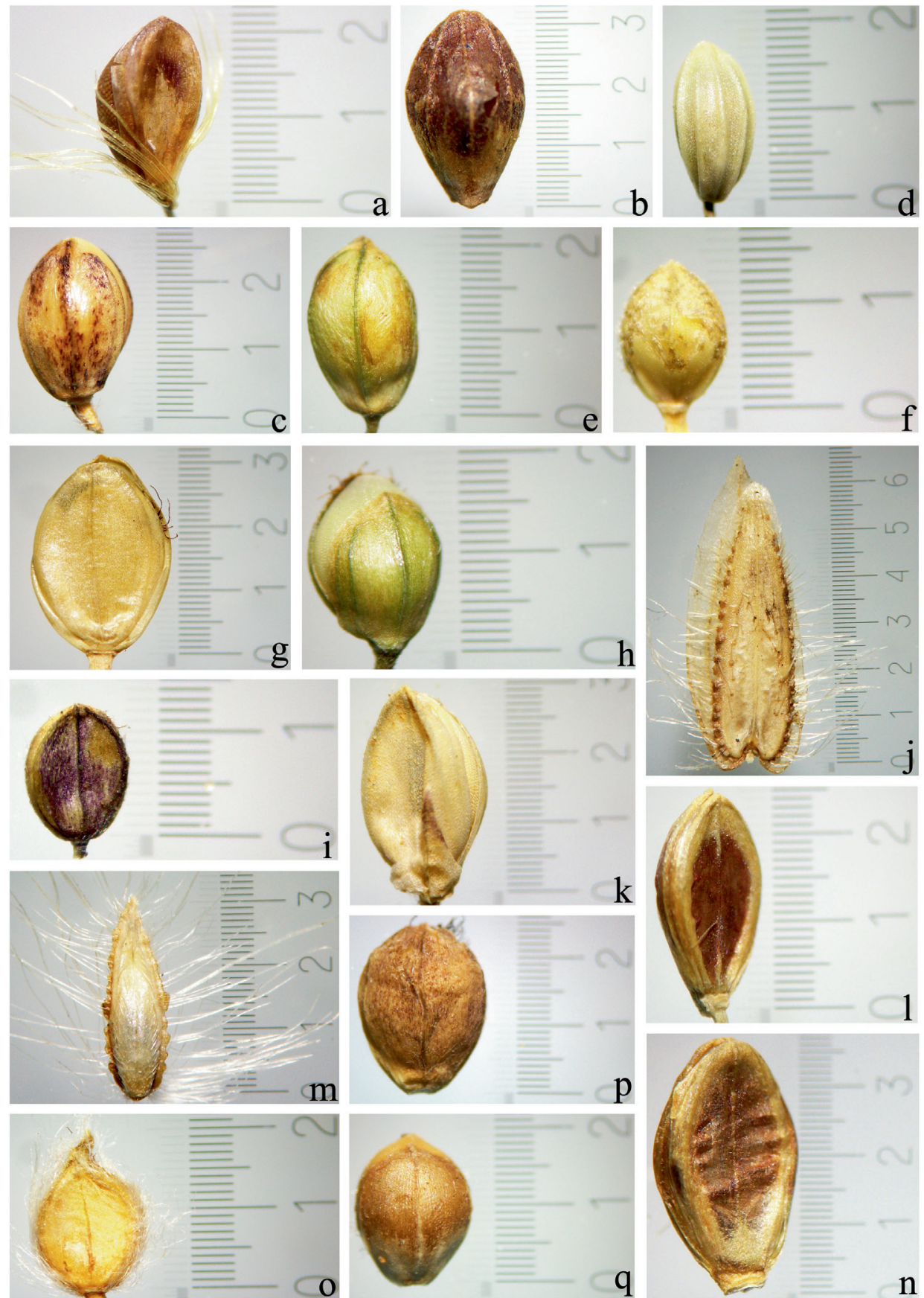

Figura 3. a. Paspalum gardnerianum (Mantovani 686): espigueta. b. P. geminiflorum (Kuhlmann 4197): espigueta. c. P. maculosum (Eiten 1607): espigueta. d. P. malacophyllum (Rodrigues 112): antécio superior, vista dorsal. e. P. mandiocanum [Rodrigues S.n. (SP440806)]: espigueta. f. P. multicaule (Longhi-Wagner 3297): espigueta. g. P. notatum (Eiten 2619): espigueta. h. P. nutans (Rodrigues 143): espigueta. i. P. paniculatum (Rodrigues 292): espigueta. j. P. pectinatum (Kuhlmann 4192): espigueta. k. P. pilosum (Longhi-Wagner 3298): espigueta. 1. P. plicatulum (Sendulsky 1127): espigueta. m. P. polyphyllum (Mantovani 533): espigueta. n. P. rojasii (Mantovani 1567): espigueta. o. P. urvillei (Eiten 1543): espigueta. p. P. virgatum (Longhi-Wagner 3293): espigueta. q. Paspalum sp.1 (Rodrigues 293): espigueta. Escala em milímetros.

Figure 3. a. Paspalum gardnerianum (Mantovani 686): spikelet. b. P. geminiflorum (Kuhlmann 4197): spikelet. c. P. maculosum (Eiten 1607): spikelet. d. P. malacophyllum (Rodrigues 112): upper anthecium, dorsal view. e. P. mandiocanum [Rodrigues s.n. (SP440806)]: spikelet. f. P. multicaule (Longhi-Wagner 3297): spikelet. g. P. notatum (Eiten 2619): spikelet. h. P. nutans (Rodrigues 143): spikelet. i. P. paniculatum (Rodrigues 292): spikelet. j. P. pectinatum (Kuhlmann 4192): spikelet. k. P. pilosum (Longhi-Wagner 3298): spikelet. 1. P. plicatulum (Sendulsky 1127): spikelet. m. P. polyphyllum (Mantovani 533): spikelet. n. P. rojasii (Mantovani 1567): spikelet. o. P. urvillei (Eiten 1543): spikelet. p. P. virgatum (Longhi-Wagner 3293): spikelet. q. Paspalum sp.1 (Rodrigues 293): spikelet. Scale in millimeters. 
Distribuição: endêmica da América do Sul. No Brasil ocorre em todas as regiões, na Amazônia, no Cerrado, na Mata Atlântica, no Pampa e no Pantanal (Valls \& Oliveira 2014).

Conservação: preocupação menor. Nativa.

Nomes populares: grama-do-campo.

Existe apenas um registro desta espécie para a RBMG-SP, realizado há 55 anos. Esta é, entretanto, a primeira vez que a espécie é formalmente referida para a Reserva. Não foram localizados novos indivíduos durante os trabalhos de campo deste estudo.

17.12. Paspalum malacophyllum Trin., Sp. Gram. 3: 271.1836.

Figura $3 \mathrm{~d}$

Material selecionado: BRASIL. São PaUlo: Mogi-Guaçu, Reserva Biológica de Mogi-Guaçu, 17-IV-2011, R.S. Rodrigues \& T.S. Filgueiras 112 (SP).

Distribuição: Américas, desde os Estados Unidos até a Argentina. No Brasil ocorre em todas as regiões, na Amazônia, na Caatinga, no Cerrado e na Mata Atlântica (Valls \& Oliveira 2014).

Conservação: preocupação menor. Nativa.

Nomes populares: capim-milhã-roxo, capim-milhãde-talo-roxo.

Esta é a primeira vez que a espécie é referida para a RBMG-SP. Ocorre em áreas abertas e bordas de mata na gleba A.

17.13. Paspalum mandiocanum Trin., Gram. Panic.: 113. 1826.

Figura 3 e

Material selecionado: BRASIL. São PaUlo: MogiGuaçu, Reserva Biológica de Mogi-Guaçu, 24-I-2012, R.S. Rodrigues \& C.V. Silva 266 (SP).

Distribuição: endêmica da América do Sul. No Brasil ocorre nas regiões Centro-Oeste, Sudeste e Sul; no Cerrado, na Mata Atlântica e no Pampa (Valls \& Oliveira 2014).

Conservação: preocupação menor. Nativa.

Nomes populares: não registrado.

Esta é a primeira vez que a espécie é registrada na RBMG-SP. Ocorre nas bordas de mata e ao longo de trilhas da gleba A. Não foram localizados indivíduos na gleba B.
17.14. Paspalum multicaule Poir., Encycl., Suppl. 4: 309. 1816.

Figura $3 \mathrm{f}$

Material selecionado: BRASIL. São PaUlo: MogiGuaçu, Reserva Biológica de Mogi-Guaçu, 24-I-2012, R.S. Rodrigues \& C.V. Silva $268 b$ (SP).

Distribuição: Américas, desde o México até o Brasil, onde ocorre nas regiões Norte, Nordeste, Centro-Oeste e Sudeste; na Amazônia e no Cerrado (Chase 1929, Oliveira \& Valls 2001).

Conservação: preocupação menor. Nativa.

Nomes populares: não registrado.

Esta é a primeira vez que a espécie é registrada na RBMG-SP. Ocorre nas bordas de mata da gleba A. Não foram localizados indivíduos na gleba B.

17.15. Paspalum notatum Flüggé, Gram. Monogr., Paspalum: 106. 1810.

Figura $3 \mathrm{~g}$

Material selecionado: BRASIL. São Paulo: Mogi-Guaçu, Reserva Biológica de Mogi-Guaçu, 16-XII-1959, G. Eiten 1598 (NY, SP).

Distribuição: Américas, desde os Estados Unidos até a Argentina. No Brasil ocorre em todas as regiões, na Amazônia, no Cerrado, na Caatinga e no Pampa (Valls \& Oliveira 2014).

Conservação: preocupação menor. Nativa.

Nomes populares: grama-batatais, capim-australiano, capim-forquilha, pensacola.

$\mathrm{O}$ último registro da espécie na RBMG-SP ocorreu há 53 anos. Não foram localizados indivíduos durante os trabalhos de campo deste estudo.

17.16. Paspalum nutans Lam., Tabl. Encycl. 1: 175. 1791.

Figura 3 h

Material selecionado: BRASIL. São PAUlo: MogiGuaçu, Reserva Biológica de Mogi-Guaçu, 25-X-2011, R.S. Rodrigues 211 (SP).

Distribuição: Américas, desde o México até o Brasil, onde ocorre nas regiões Norte, Nordeste, Sudeste e Sul; na Amazônia, no Cerrado e na Mata Atlântica (Valls \& Oliveira 2014).

Conservação: preocupação menor. Nativa.

Nomes populares: capim-touceira. 

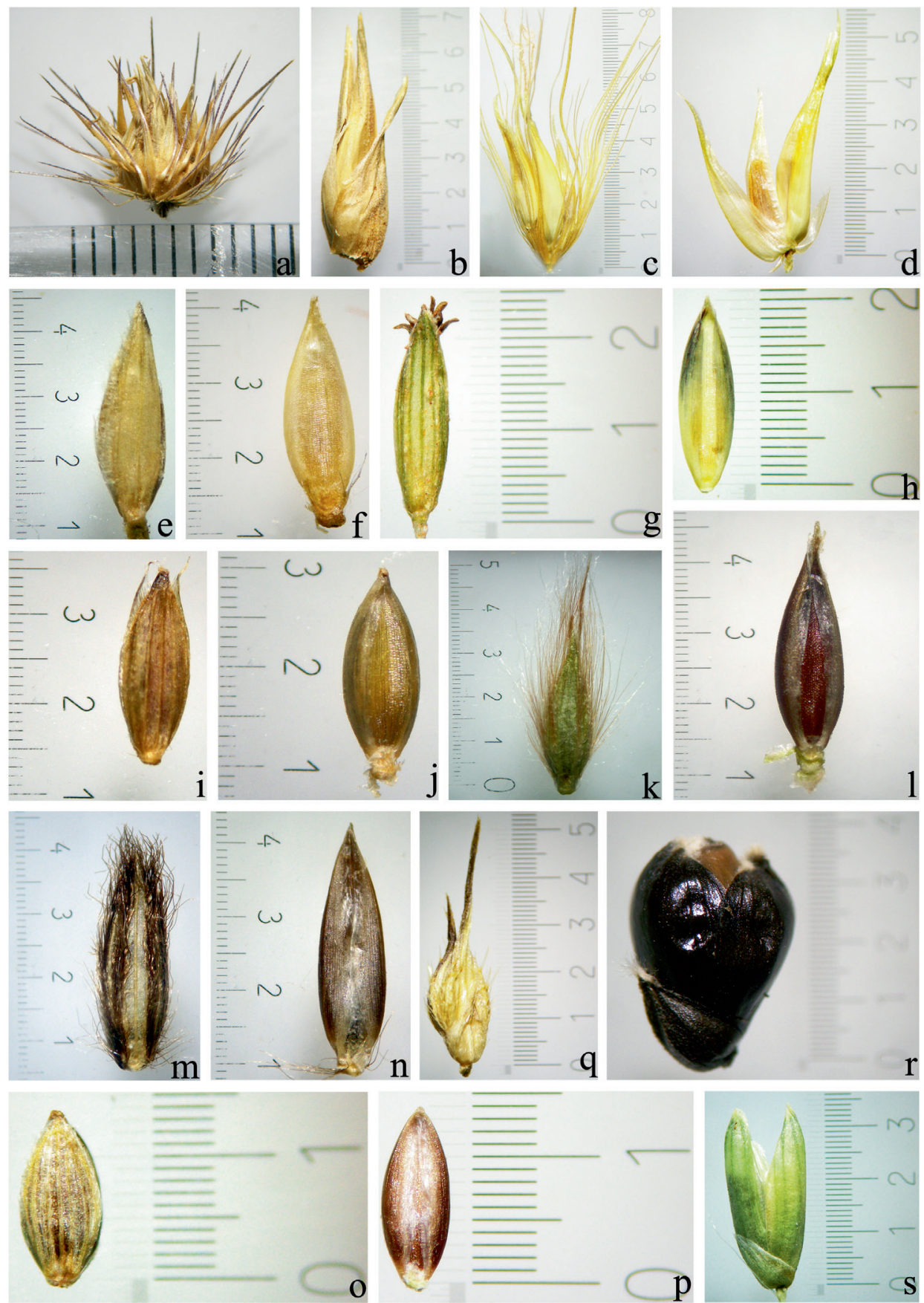

Figura 4. a-b. Cenchrus echinatus (Eiten 1553): a. espigueta com invólucro de cerdas espinescentes; b. espigueta sem o invólucro. c-d. C. purpureus (Rodrigues 303): c. espigueta com invólucro de cerdas plumosas; d. espigueta sem o invólucro. e-f. Digitaria ciliaris (Eiten 2658): e. espigueta; f. antécio superior. g-h. D. eriantha (Rodrigues 231): g. espigueta; h. antécio superior. i-j. D. horizontalis (Eiten 1552): i. espigueta; j. antécio superior. k-1. D. insularis (Rodrigues 128): k. espigueta; 1. antécio superior. m-n. D. neesiana (Mantovani 1048): m. espigueta; n. antécio superior. o-p. D. violascens (Rodrigues 182): o. espigueta; p. antécio superior. q. Echinochloa crus-galli (Monteiro 7680): espigueta. r. Lasiacis ligulata (Rodrigues 125): espigueta. s. Megathyrsus maximus (Rodrigues 144): espigueta. Escala em milímetros.

Figure 4. a-b. Cenchrus echinatus (Eiten 1553): a. spikelet with spinescent involucre; b. spikelet without involucre. c-d. C. purpureus (Rodrigues 303): c. spikelet with plumose involucre; d. spikelet without involucre. e-f. Digitaria ciliaris (Eiten 2658): e. spikelet; f. upper anthecium. g-h. D. eriantha (Rodrigues 231): g. spikelet; h. upper anthecium. i-j. D. horizontalis (Eiten 1552): i. spikelet; j. upper anthecium. k-1. D. insularis (Rodrigues 128): k. spikelet; 1. upper anthecium. m-n. D. neesiana (Mantovani 1048): m. spikelet; n. upper anthecium. o-p. D. violascens (Rodrigues 182): o. spikelet; p. upper anthecium. q. Echinochloa crus-galli (Monteiro 7686): spikelet. r. Lasiacis ligulata (Rodrigues 125): spikelet. s. Megathyrsus maximus (Rodrigues 144): spikelet. Scale in millimeters. 
Esta é a primeira vez que a espécie é registrada para a RBMG-SP. Ocorre com abundância às margens do Córrego do Cortado, na gleba A.

17.17. Paspalum paniculatum L., Syst. Nat., ed. 10. 2: 855.1759.

Figura $3 \mathrm{i}$

Material selecionado: BRASIL. São Paulo: Mogi-Guaçu, Reserva Biológica de Mogi-Guaçu, 21-VIII-2012, R.S. Rodrigues \& M. Pastore 306 (SP).

Distribuição: América, África e Austrália. No Brasil ocorre em todas as regiões, na Amazônia, no Cerrado, na Mata Atlântica, no Pampa e no Pantanal (Valls \& Oliveira 2014).

Conservação: preocupação menor. Nativa.

Nomes populares: capim-marmelada, capim-milhãbranca, grama-de-pernambuco.

Esta é a primeira vez que a espécie é registrada na RBMG-SP. Ocorre em ambas as glebas. Na gleba A, em bordas de mata, nas proximidades da sede, e margens do Córrego do Cortado; na gleba B, ocorre nas bordas de mata.

17.18. Paspalum pectinatum Nees ex Trin., Sp. Gram. 1: 78.1828.

Figura $3 \mathrm{j}$

Material selecionado: BRASIL. São Paulo: MogiGuaçu, Reserva Biológica de Mogi-Guaçu, 27-I-1981, M. Sugiyama \& W. Mantovani 7 (SP).

Distribuição: Américas, desde o México até o Brasil, onde ocorre em todas as regiões, na Amazônia, no Cerrado e na Mata Atlântica (Valls \& Oliveira 2014).

Conservação: preocupação menor. Nativa.

Nomes populares: grama-das-pedras.

O último registro da espécie para RBMG-SP foi realizado há 33 anos. Não foram encontrados novos indivíduos durante os trabalhos de campo deste estudo.

17.19. Paspalum pilosum Lam., Tabl. Encycl. 1: 175. 1791.

Figura $3 \mathrm{k}$

Material selecionado: BRASIL. São Paulo: MogiGuaçu, Reserva Biológica de Mogi-Guaçu, 25-I-2012, R.S. Rodrigues \& C.V. Silva 281 (SP).

Distribuição: Américas, desde o México até o Brasil, onde ocorre em todas as regiões, na Amazônia, na
Caatinga, no Cerrado, na Mata Atlântica (Valls \& Oliveira 2014) e no Pantanal (Allem \& Valls 1987).

Conservação: preocupação menor. Nativa.

Nomes populares: capim-felpudo.

Um único indivíduo foi amostrado durante a realização desse estudo. Ocorre na gleba $\mathrm{A}$, nas proximidades da sede.

17.20. Paspalum plicatulum Michx., Fl. Bor. Amer. 1: 45.1803.

Figura 31

Material selecionado: BRASIL. SÃo Paulo: MogiGuaçu, Reserva Biológica de Mogi-Guaçu, 24-I-2012, R.S. Rodrigues \& C.V. Silva 277 (SP).

Distribuição: Américas, desde os Estados Unidos até a Argentina. No Brasil ocorre em todas as regiões e em todos os biomas (Valls \& Oliveira 2014).

Conservação: preocupação menor. Nativa.

Nomes populares: não registrado.

Espécie bem documentada na RBMG-SP. Encontrada em áreas antropizadas, em bordas de mata e beira de estradas da gleba A. Não foram localizados indivíduos nas porções interioranas da Reserva, nem na gleba B.

17.21. Paspalum polyphyllum Nees ex Trin., Gram. Panic. 114. 1826.

Figura $3 \mathrm{~m}$

Material selecionado: BRASIL. São Paulo: MogiGuaçu, Reserva Biológica de Mogi-Guaçu, 8-IV-1980, W. Mantovani 533 (SP).

Distribuição: endêmica da América do Sul. No Brasil ocorre nas regiões Nordeste, Centro-Oeste, Sudeste e Sul; na Amazônia, na Caatinga, no Cerrado, na Mata Atlântica e no Pampa (Valls \& Oliveira 2014).

Conservação: preocupação menor. Nativa.

Nomes populares: capim-lanoso.

O único registro da ocorrência da espécie na RBMG-SP foi realizado há 34 anos. Novos indivíduos não foram localizados durante os trabalhos de campo deste estudo.

17.22. Paspalum rojasii Hack., Repert. Spec. Nov. Regni Veg. 7: 369. 1909.

Figura $3 n$

Material selecionado: BRASIL. São PAuLo: MogiGuaçu, Reserva Biológica de Mogi-Guaçu, 24-I-2012, R.S. Rodrigues \& C.V. Silva $267 b$ (SP). 

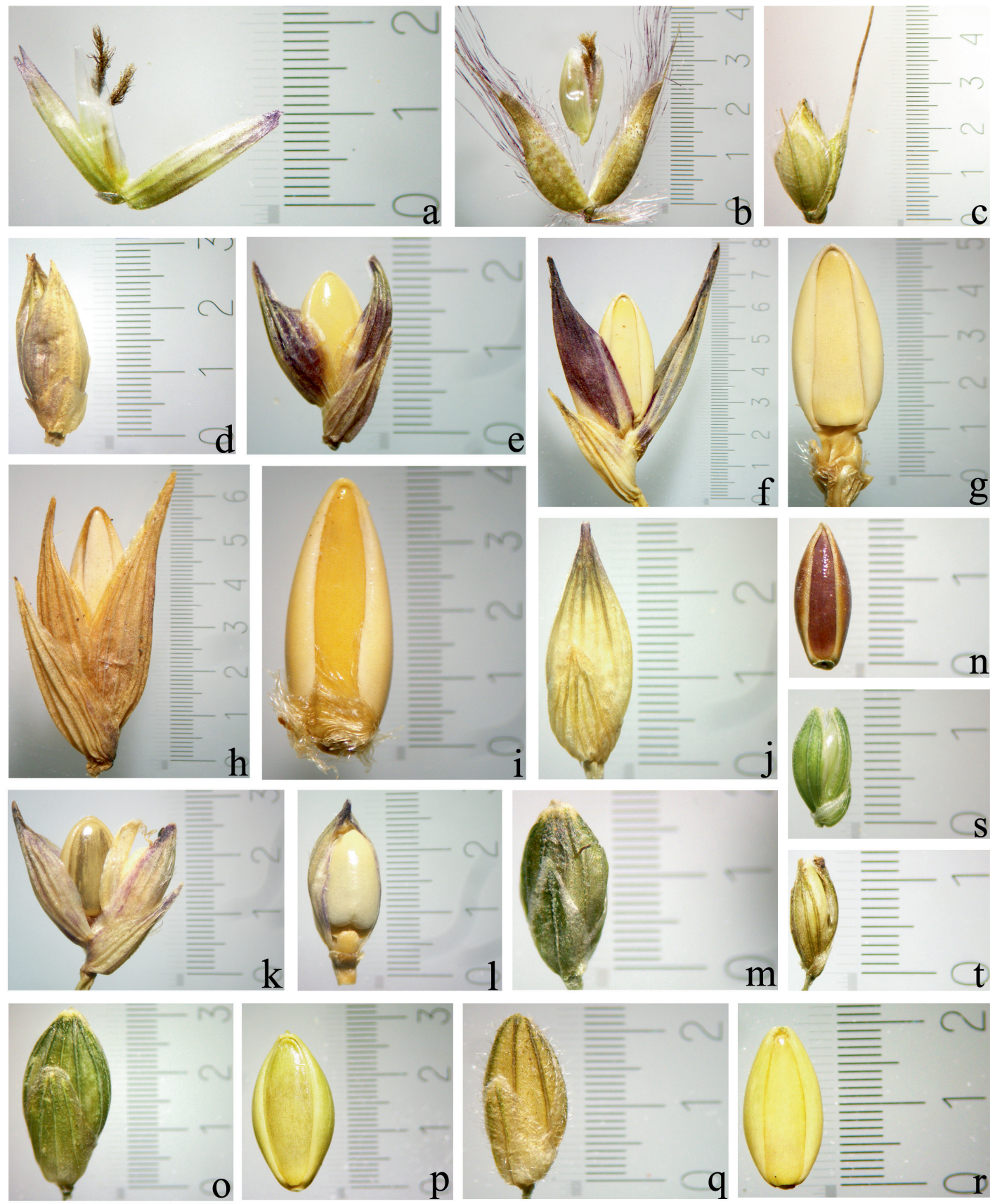

$\mathrm{m}$
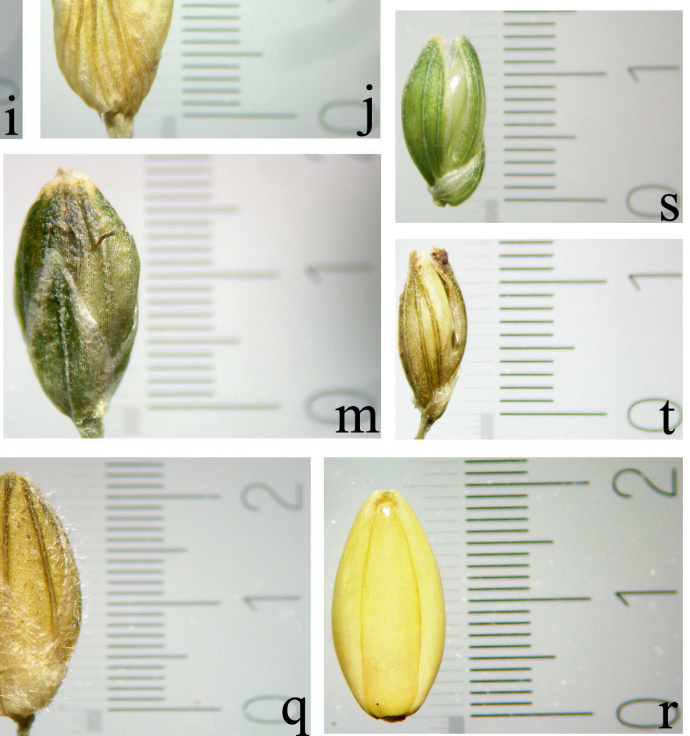

Figura 5. a. Melinis minutiflora (Rodrigues 131): espigueta. b. M. repens (Rodrigues 153): espigueta, antécio superior destacado. c. Oplismenus hirtellus [Rodrigues s.n. (SP440801)]: espigueta. d. Panicum aquaticum (Eiten 1940): espigueta. e. P. campestre (Eiten 1669): espigueta. f-g. P. cervicatum (Rodrigues 157): f. espigueta; g. antécio superior (notar estípite basal). h-i. P. olyroides (Mantovani 563): h. espigueta; i. antécio superior (notar tricomas basais). j. P. peladoense (Sugiyama 40): espigueta. k-1. P. rudgei (Mantovani 387): k. espigueta; l. lema I e antécio superior (notar estípite basal). m-n. P. sellowii [Rodrigues s.n. (SP440804)]: m. espigueta; $\mathrm{n}$. antécio superior. o-p. Parodiophyllochloa ovulifera (Rodrigues 129): o. espigueta; p. antécio superior. q-r. P. pantricha (Rodrigues 138): q. espigueta; r. antécio superior. s. Rugoloa pilosa (Rodrigues 265): espigueta. t. R. polygonata (Rodrigues 142): espigueta. Escala em milímetros.

Figure 5. a. Melinis minutiflora (Rodrigues 131): spikelet. b. M. repens (Rodrigues 153): spikelet, upper anthecium detached. c. Oplismenus hirtellus [Rodrigues s.n. (SP440801)]: spikelet. d. Panicum aquaticum (Eiten 1940): spikelet. e. P. campestre (Eiten 1669): spikelet. f-g. P. cervicatum (Rodrigues 157): f. spikelet; g. upper anthecium (see basal stipe). h-i. P. olyroides (Mantovani 563): h. spikelet; i. upper anthecium (see basal trichomes). j. P. peladoense (Sugiyama 40): spikelet. k-1. P. rudgei (Mantovani 387): k. spikelet; 1. lemma I and upper anthecium (see basal stipe). m-n. P. sellowii [Rodrigues s.n. (SP440804)]: m. spikelet; n. upper anthecium. o-p. Parodiophyllochloa ovulifera (Rodrigues 129): o. spikelet; p. upper anthecium. q-r. P. pantricha (Rodrigues 138): q. spikelet; r. upper anthecium. s. Rugoloa pilosa (Rodrigues 265): spikelet. t. R. polygonata (Rodrigues 142): spikelet. Scale in millimeters. 
Distribuição: endêmica da América do Sul, ocorrendo no Brasil e Paraguai. No Brasil ocorre nas regiões Nordeste, Centro-Oeste, Sudeste e Sul; na Caatinga, no Cerrado e na Mata Atlântica (Valls \& Oliveira 2014).

Conservação: preocupação menor. Nativa.

Nomes populares: não registrado.

Na RBMG-SP, é encontrada nas bordas de mata da gleba A. Não foram encontrados indivíduos nas porções interioranas da Reserva, nem na gleba B.

17.23. Paspalum urvillei Steud., Syn. Pl. Glumac. 1: 24. 1855 [1853].

Figura 3 o

Material selecionado: BRASIL. São Paulo: MogiGuaçu, Reserva Biológica de Mogi-Guaçu, 27-X-2011, R.S. Rodrigues 234 (SP).

Distribuição: América, África, Ásia e Austrália. No Brasil ocorre nas regiões Nordeste, Centro-Oeste, Sudeste e Sul; no Cerrado, na Mata Atlântica e no Pampa (Valls \& Oliveira 2014).

Conservação: preocupação menor. Nativa.

Nomes populares: capim-das-roças.

O último registro da espécie para a RBMG-SP havia sido realizado há 55 anos. Um único indivíduo foi amostrado em área antropizada da gleba A, na porção oeste da Reserva. Não foram localizados outros indivíduos no interior da Reserva, nem na gleba B.

17.24. Paspalum virgatum L., Syst. Nat., ed. 10. 2: 855. 1759.

Figura $3 \mathrm{p}$

Material selecionado: BRASIL. São Paulo: MogiGuaçu, Reserva Biológica de Mogi-Guaçu, 24-I-2012, R.S. Rodrigues \& C.V. Silva 278 (SP).

Distribuição: Américas, desde os Estados Unidos até a Argentina. No Brasil ocorre em todas as regiões, na Amazônia, no Cerrado, na Mata Atlântica e no Pantanal (Valls \& Oliveira 2014).

Conservação: preocupação menor. Nativa.

Nomes populares: não registrado.

Esta é a primeira vez que a espécie é registrada para a RBMG-SP. Ocorre em bancos de areia ao longo do Córrego do Cortado e em áreas antropizadas nas bordas de mata da gleba $\mathrm{A}$.
17.25. Paspalum sp. 1

Figura $3 \mathrm{q}$

Material selecionado: BRASIL. São Paulo: Mogi-Guaçu, Reserva Biológica de Mogi-Guaçu, 19-VI-2012, R.S. Rodrigues 293 (SP).

Espécie morfologicamente semelhante a Paspalum mandiocanum, porém distinta pelas espiguetas obovadas a elíptico-obovadas e antécio superior fortemente estramíneo na maturidade, enquanto $P$. mandiocanum apresenta espiguetas oblongo-elípticas e antécio superior esverdeado a levemente estramíneo quando maduro. Além disso, Paspalum sp. 1 apresenta o lema I sem nervura central e com coloração central diferenciada, conspícua nas espiguetas maduras, o que não ocorre em P. mandiocanum.

Assemelha-se fortemente a $P$. squamulatum E. Fourn., quanto ao hábito, tamanho e forma das espiguetas, além do comprimento e número de nervuras da gluma II, mas difere pela presença de tricomas inconspícuos nas margens e em direção ao ápice das espiguetas, e pelas características do lema I (cf. acima).

Apresenta, também, afinidade morfológica com $P$. corcovadense Raddi quanto ao seu aspecto vegetativo; em $P$. corcovadense, entretanto, as espiguetas estão densamente agrupadas ao longo dos ramos da inflorescência e são tipicamente elípticas, conspicuamente agudas. Além do mais, os caracteres do lema I e do antécio superior de Paspalum sp. 1 não são observados em $P$. corcovadense.

Um maior número de coletas torna-se necessário para esclarecer as afinidades e identidade deste espécime, já que na RBMG-SP apenas um indivíduo foi encontrado.

18. Pseudechinolaena Stapf, Fl. Trop. Afr. 9: 494. 1919.

18.1. Pseudechinolaena polystachya (Kunth) Stapf, Flor. Trop. Afr. 9: 495. 1919.

Figura $6 \mathrm{c}$

Material selecionado: BRASIL. São Paulo: Mogi-Guaçu, Reserva Biológica de Mogi-Guaçu, 15-VI-2011, R.S. Rodrigues 137 (SP).

Distribuição: regiões tropicais da África, da Índia, da China e da América, onde se distribui desde o México até a Argentina. No Brasil ocorre em todas as regiões, no Cerrado e na Mata Atlântica (Filgueiras 2014c). 

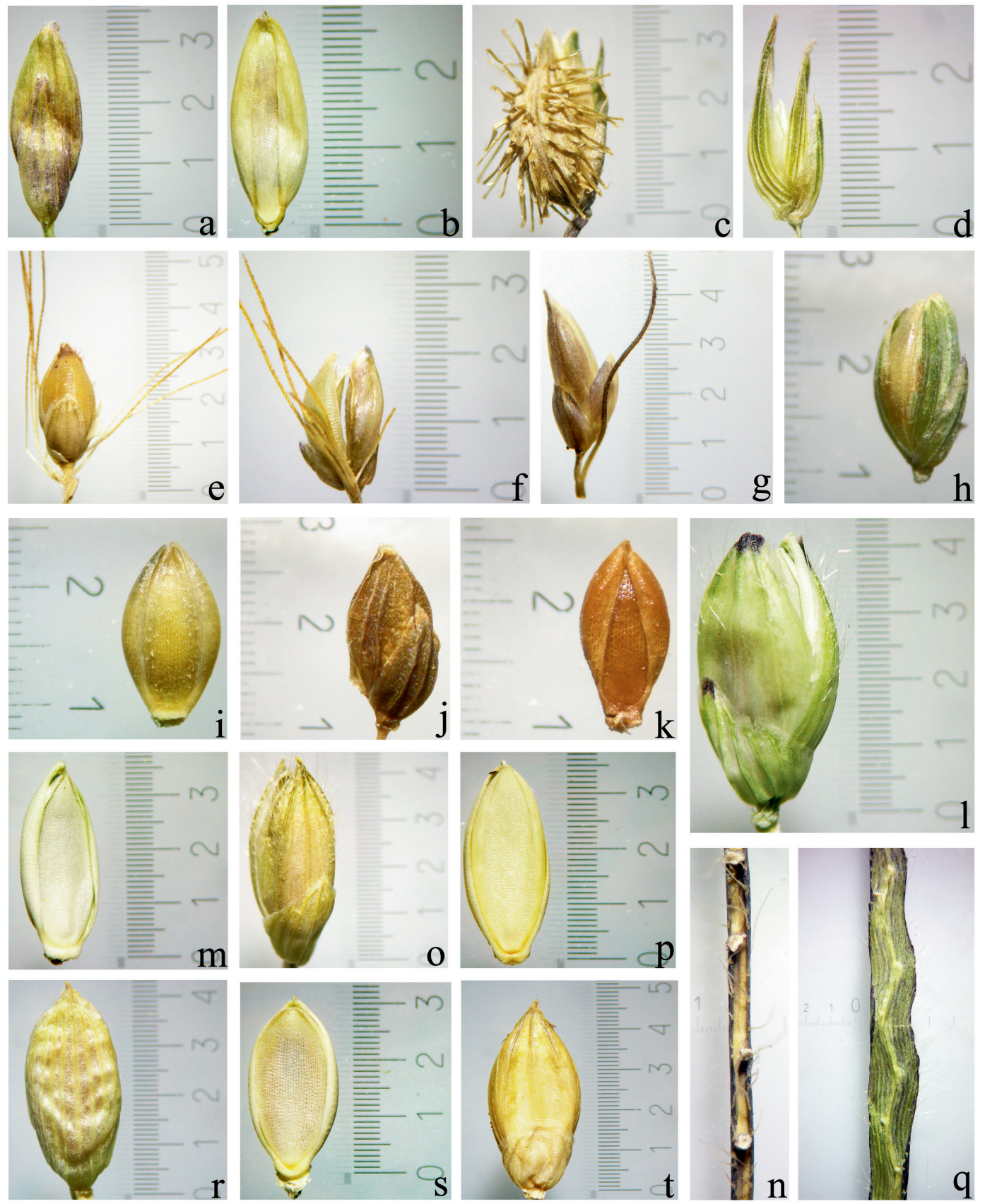

Figura 6. a-b. Parodiophyllochloa penicillata (Rodrigues 255): a. espigueta; b. antécio superior. c. Pseudechinolaena polystachya (Rodrigues 137): espigueta. d. Sacciolepis indica (Rodrigues 214): espigueta. e. Setaria parviflora (Mantovani 1825): espigueta com cerdas. f. S. sphacelata (Rodrigues 276): espigueta com cerdas. g. S. sulcata (Mattos 12286): espigueta com cerda única. h-i. Trichanthecium parvifolium (Rodrigues 122): h. espigueta; i. antécio superior. j-k. T. schwackeanum (Eiten 3513): j. espigueta; k. antécio superior. 1-n. Urochloa brizantha (Rodrigues 130): 1. espigueta; m. antécio superior; n. ráquis. o-q. U. decumbens (Rodrigues 204): o. espigueta; p. antécio superior; q. ráquis. r-s. U. humidicola (Rodrigues 279): r. espigueta; s. antécio superior. t. U. plantaginea (Eiten 2664): espigueta. Escala em milímetros.

Figure 6. a-b. Parodiophyllochloa penicillata (Rodrigues 255): a. spikelet; b. upper anthecium. c. Pseudechinolaena polystachya (Rodrigues 137): spikelet. d. Sacciolepis indica (Rodrigues 214): spikelet. e. Setaria parviflora (Mantovani 1825): spikelet with bristles. f. S. sphacelata (Rodrigues 276): spikelet with bristles. g. S. sulcata (Mattos 12286): spikelet with a single bristle. h-i. Trichanthecium parvifolium (Rodrigues 122): h. spikelet; i. upper anthecium. j-k. T. schwackeanum (Eiten 3513): j. spikelet; k. upper anthecium. 1-n. Urochloa brizantha (Rodrigues 130): 1. spikelet; m. upper anthecium; n. rachis. o-q. U. decumbens (Rodrigues 204): o. spikelet; p. upper anthecium; q. rachis. r-s. U. humidicola (Rodrigues 279): r. spikelet; s. upper anthecium. t. U. plantaginea (Eiten 2664): spikelet. Scale in millimeters. 
Conservação: preocupação menor. Nativa.

Nomes populares: não registrado.

Esta é a primeira vez que a espécie é registrada na RBMG-SP. Ocorre em ambas as glebas, ao longo das trilhas, em locais úmidos e sombreados, e nas proximidades da sede.

19. Rugoloa Zuloaga, Plant Syst. Evol. 2014 (29 Mar 2014 epub.).

Chave para identificação das espécies de Rugoloa da Reserva Biológica de Mogi-Guaçu

1. Lígula ausente; inflorescência composta por ramos unilaterais alternos; espiguetas secundas 19.1. R. pilosa

1. Lígula presente; inflorescência em panícula típica, aberta; espiguetas não secundas 19.2. R. polygonata

19.1. Rugoloa pilosa (Sw.) Zuloaga, Plant Syst. Evol. 2014 (29 Mar 2014 epub.).

Figura $5 \mathrm{~s}$

Material selecionado: BRASIL. São Paulo: MogiGuaçu, Reserva Biológica de Mogi-Guaçu, 24-I-2012, R.S. Rodrigues \& C.V. Silva 265 (SP).

Distribuição: Américas, desde os Estados Unidos até a Argentina. No Brasil ocorre em todas as regiões e biomas (Rodrigues 2014a).

Conservação: preocupação menor. Nativa.

Nomes populares: capim-de-anta, grama-de-sombra.

Esta é a primeira vez que a espécie é referida para a RBMG-SP. Ocorre no interior de matas da gleba $\mathrm{B}$, ao longo das trilhas e margens do Córrego do Capitinguinha.

19.2. Rugoloa polygonata (Schrad.) Zuloaga, Plant Syst. Evol. 2014 (29 Mar 2014 epub).

Figura $5 \mathrm{t}$

Material selecionado: BRASIL. São Paulo: Mogi-Guaçu, Reserva Biológica de Mogi-Guaçu, 21-VIII-2012, R.S. Rodrigues \& M. Pastore 299 (SP).

Distribuição: Américas, desde o México até a Argentina. No Brasil ocorre em todas as regiões e biomas (Rodrigues 2014a).

Conservação: preocupação menor. Nativa.

Nomes populares: capim-do-brejo.
Esta é a primeira vez que a espécie é registrada para a RBMG-SP. Ocorre no interior de mata da gleba $\mathrm{B}$, ao longo das trilhas e junto às margens do Córrego do Capitinguinha.

20. Sacciolepis Nash, Man. Fl. N. States: 89. 1901.

20.1. Sacciolepis indica (L.) Chase, Proc. Biol. Soc. Wash. 21: 8. 1908.

Figura $6 \mathrm{~d}$

Material selecionado: BRASIL. São Paulo: Mogi-Guaçu, Reserva Biológica de Mogi-Guaçu, 19-VI-2012, R.S. Rodrigues 291 (SP).

Distribuição: Ásia, América, África tropical, Polinésia e Oceania. Na América ocorre desde os Estados Unidos até a Bolívia e sul do Brasil (Judziewicz 1990, Genaro 2011). No Brasil ocorre nas regiões Nordeste, Sudeste e Sul; na Mata Atlântica (Shirasuna \& Oliveira 2014a) e no Cerrado.

Conservação: preocupação menor. Exótica.

Nomes populares: não registrado.

Referida pela primeira vez para a flora paulista por Longhi-Wagner et al. (2011), é aqui registrada pela primeira vez para a RBMG-SP. Ocorre em áreas úmidas de ambas as glebas, junto às margens do Córrego do Cortado e do Capitinguinha.

21. Setaria P. Beauv., Ess. Agrostogr.: 51. 1812.

Chave para identificação das espécies de Setaria da Reserva Biológica de Mogi-Guaçu

1. Lâminas plicadas; inflorescência em panícula contraída a subcontraída ..... 21.3. S. sulcata

1. Lâminas planas; inflorescência em panícula espiciforme

2. Colmos cilíndricos; inflorescência 2-9,5 cm de comprimento 21.1. S. parviflora

2. Colmos lateralmente comprimidos; inflorescência 10-40 cm de comprimento 21.2. S. sphacelata

21.1. Setaria parviflora (Poir.) Kerguélen, Lejeunia 120: 161. 1987.

Figura $6 \mathrm{e}$

Material selecionado: BRASIL. SÃo Paulo: MogiGuaçu, Reserva Biológica de Mogi-Guaçu, 24-I-2012, R.S. Rodrigues \& C.V. Silva 280 (SP). 
Distribuição: Américas. No Brasil ocorre em todas as regiões, na Amazônia, na Caatinga, no Cerrado, na Mata Atlântica e no Pantanal (Shirasuna \& Rodrigues 2014).

Conservação: preocupação menor. Nativa.

Nomes populares: capim-rabo-de-gato, capim-rabode-raposa.

Uma única população desta espécie foi localizada em área antropizada da RBMG-SP. Ocorre em bordas de mata, na porção oeste da gleba A.

21.2. Setaria sphacelata (Schumach.) Stapf \& C.E. Hubb., Fl. Trop. Afr. 9: 795. 1930.

Figura $6 \mathrm{f}$

Material selecionado: BRASIL. São Paulo: MogiGuaçu, Reserva Biológica de Mogi-Guaçu, 24-I-2012, R.S. Rodrigues \& C.V. Silva 276 (SP).

Distribuição: Américas, desde os Estados Unidos até a Argentina. No Brasil ocorre nas regiões Norte, Nordeste, Sudeste e Sul; na Amazônia, no Cerrado e na Mata Atlântica (Shirasuna \& Rodrigues 2014).

Conservação: preocupação menor. Exótica.

Nomes populares: não registrado.

Este é o primeiro registro da espécie na RBMG-SP. Frequentemente utilizada como forrageira, sua presença na RBMG-SP pode estar associada às atividades agrícolas das propriedades vizinhas. Uma única população foi localizada em área antropizada, ocorrendo em bordas de mata, na porção oeste da gleba $\mathrm{A}$.

21.3. Setaria sulcata Raddi, Agrostogr. Bras.: 50. 1823.

Figura $6 \mathrm{~g}$

Material selecionado: BRASIL. São Paulo: MogiGuaçu, Reserva Biológica de Mogi-Guaçu, 24-V-1965, J.R. Mattos 12286 (SP).

Distribuição: Américas, desde o México até a Argentina. No Brasil ocorre em todas as regiões, na Amazônia, na Caatinga, no Cerrado e na Mata Atlântica (Shirasuna \& Rodrigues 2014).

Conservação: preocupação menor. Nativa.

Nomes populares: capim-palmeirinha, capim-canoão.

Esta é a primeira vez que esta espécie é referida para a RBMG-SP. Ocorre na gleba A, no interior de áreas de mata, ao longo de trilhas e no "Bosque do Pau-Brasil”, nas proximidades da sede.
22. Steinchisma Raf., Bull. Bot. (Geneve) 1: 220. 1830.

Chave para identificação das espécies de Steinchisma da Reserva Biológica de Mogi-Guaçu

1. Plantas eretas; inflorescência em panícula contraída; espiguetas 1,7-2,2 mm de comprimento 22.1. S. decipiens

1. Plantas decumbentes, menos frequentemente eretas; inflorescência em panícula laxa a subcontraída; espiguetas 1-1,5 mm de comprimento 22.2. S. laxum

22.1. Steinchisma decipiens (Nees ex Trin.) W.V. Br., Mem. Torrey Bot. Club 23(3): 20. 1977.

Figura $2 \mathrm{f}$

Material selecionado: BRASIL. São Paulo: Mogi-Guaçu, Reserva Biológica de Mogi-Guaçu, 21-XII-2011, R.S. Rodrigues \& C.V. Silva 249 (SP).

Distribuição: endêmica da América do Sul. No Brasil ocorre em todas as regiões, na Amazônia e no Cerrado (Zuloaga et al. 1998, Shirasuna \& Oliveira 2014b).

Conservação: preocupação menor. Nativa.

Nomes populares: não registrado.

Frequente em áreas úmidas da RBMG-SP. Ocorre em ambas as glebas, nas margens dos Córregos do Cortado e do Capitinguinha.

22.2. Steinchisma laxum (Sw.) Zuloaga, Amer. J. Bot. 90(5): 817. 2003.

Figura $2 \mathrm{~g}$

Material selecionado: BRASIL. São Paulo: MogiGuaçu, Reserva Biológica de Mogi-Guaçu, 24-I-2012, R.S. Rodrigues \& C.V. Silva 272 (SP).

Distribuição: Américas, desde os Estados Unidos até a Argentina. No Brasil ocorre em todas as regiões e biomas (Shirasuna \& Oliveira 2014b).

Conservação: preocupação menor. Nativa.

Nomes populares: não registrado.

Esta é a primeira vez que a espécie é referida para a RBMG-SP. Ocorre em ambas as glebas, às margens dos Córregos do Cortado e do Capitinguinha. É encontrada com menor frequência em áreas úmidas no interior de mata.

23. Trichanthecium Zuloaga \& Morrone, Syst. Bot. Monogr. 94: 13. 2011. 
Chave para identificação das espécies de

Trichanthecium da Reserva Biológica de Mogi-Guaçu

1. Plantas anuais; lâminas $1,2-3 \times 0,2-0,5 \mathrm{~cm}$; inflorescência 1,5-4 cm de comprimento; pedicelos 0,3-0,6 cm de comprimento 23.1. T. parvifolium

1. Plantas perenes; lâminas (2-)3-6 × 0,5-1,2 cm; inflorescência $5-15 \mathrm{~cm}$ de comprimento; pedicelos 1-3,5(-4) cm de comprimento 23.2. T. schwackeanum

23.1. Trichanthecium parvifolium (Lam.) Zuloaga \& Morrone, Syst. Bot. Monogr. 94: 59. 2011.

Figura 6 h-i

Material selecionado: BRASIL. São PAULO: Mogi-Guaçu, Reserva Biológica de Mogi-Guaçu, 21-VIII-2012, R.S. Rodrigues \& M. Pastore 302 (SP).

Distribuição: regiões tropicais e subtropicais da América. No Brasil ocorre em todas as regiões e biomas (Rodrigues 2014b).

Conservação: preocupação menor. Nativa.

Nomes populares: capim-barbicha, capim-da-folhaestreita, capim-roxo.

Encontrada em áreas abertas, semiabertas e nas margens de trilhas da gleba A, formando densas populações de distribuição esparsa.

23.2. Trichanthecium schwackeanum (Mez) Zuloaga \& Morrone, Syst. Bot. Monogr. 94: 74. 2011.

Figura $6 \mathrm{j}-\mathrm{k}$

Material selecionado: BRASIL. São Paulo: Mogi-Guaçu, Reserva Biológica de Mogi-Guaçu, 4-XII-1961, G. Eiten 3513 (SP).

Distribuição: regiões tropicais e subtropicais da América. No Brasil ocorre em todas as regiões e biomas (Rodrigues 2014b).

Conservação: preocupação menor. Nativa.

Nomes populares: capim-do-banhado.

Esta é a primeira vez que a espécie é referida para a RBMG-SP, com base em um único registro realizado há mais de 50 anos. Presume-se que plantas desta espécie passem despercebidas pelos coletores, principalmente devido à sua grande semelhança com T. parvifolium.
24. Urochloa P. Beauv., Ess. Agrostogr.: 52. 1812.

Chave para identificação das espécies de Urochloa da Reserva Biológica de Mogi-Guaçu

1. Gluma I subigual à espigueta ..... 24.3. U. humidicola

1. Gluma I até a metade do comprimento da espigueta

2. Plantas anuais; bainhas e lâminas glabras; espiguetas glabras 24.4. U. plantaginea

2. Plantas perenes; bainhas e lâminas pilosas; espiguetas pilosas

3. Plantas estoloníferas; ráquis $2-4 \mathrm{~mm}$ de largura; espiguetas 2-seriadas sobre a ráquis 24.2. U. decumbens

3. Plantas eretas a semidecumbentes; ráquis até $1 \mathrm{~mm}$ de largura; espiguetas 1 -seriadas sobre a ráquis, raro 2-seriadas 24.1. U. brizantha

24.1. Urochloa brizantha (Hochst. ex A. Rich.) R.D. Webster, Austral. Paniceae: 223. 1987.

Figura 6 1-n

Material selecionado: BRASIL. São Paulo: MogiGuaçu, Reserva Biológica de Mogi-Guaçu, 24-I-2012, R.S. Rodrigues \& C.V. Silva 262 (SP).

Distribuição: África, América tropical e Austrália. No Brasil ocorre em todas as regiões, na Caatinga, no Cerrado, na Mata Atlântica, no Pampa e no Pantanal (Sendulsky 1978, Shirasuna 2014b).

Conservação: preocupação menor. Exótica.

Nomes populares: capim-braquiária, braquiarão, brizantão.

Esta é a primeira vez que esta espécie é referida para RBMG-SP. Encontra-se amplamente disseminada pelas áreas alteradas de ambas as glebas, mais frequentemente nas bordas de mata, clareiras, campos e ao longo das trilhas mais abertas da gleba A.

24.2. Urochloa decumbens (Stapf) R.D. Webster, Austral. Paniceae: 234. 1987.

Figura 6 o-q

Material selecionado: BRASIL. São Paulo: Mogi-Guaçu, Reserva Biológica de Mogi-Guaçu, 15-IX-2011, R.S. Rodrigues 204 (SP).

Distribuição: África, América Central, América do Sul e Austrália. No Brasil ocorre em todas as regiões, na Amazônia, no Cerrado, no Pampa e no Pantanal (Shirasuna 2014b). 
Conservação: preocupação menor. Exótica.

Nomes populares: capim-braquiária.

Esta espécie já havia sido referida para a RBMG-SP por Giudice-Neto (2010), entretanto, nenhum espécime foi localizado nos herbários consultados. Ocorre formando pequenas populações nas proximidades da sede, na gleba $\mathrm{A}$.

24.3. Urochloa humidicola (Rendle) Morrone \& Zuloaga, Darwiniana 31: 80. 1992.

Figura 6 r-s

Material selecionado: BRASIL. São Paulo: MogiGuaçu, Reserva Biológica de Mogi-Guaçu, 24-I-2012, R.S. Rodrigues \& C.V. Silva 279 (SP).

Distribuição: África e América do Sul, desde o Panamá até a Argentina. No Brasil ocorre em todas as regiões, na Amazônia, na Caatinga, no Cerrado, na Mata Atlântica e no Pampa (Shirasuna 2014b).

Conservação: preocupação menor. Exótica.

Nomes populares: capim-quicuio.

Esta é a primeira vez que a espécie é registrada na RBMG-SP. Ocorre em áreas antropizadas da gleba A, junto às bordas de mata com a rodovia na porção oeste da Reserva.

\subsection{Urochloa plantaginea (Link) R.D. Webster,} Syst. Bot. 13: 607. 1988.

Figura $6 \mathrm{t}$

Material selecionado: BRASIL. São Paulo: Mogi-Guaçu, Reserva Biológica de Mogi-Guaçu, 18-IV-1961, G. Eiten \& L.T. Eiten 2664 (SP).

Distribuição: África e Américas, desde os Estados Unidos até a Argentina. No Brasil ocorre em todas as regiões, na Amazônia, na Caatinga, no Cerrado, na Mata Atlântica e no Pampa (Shirasuna 2014b).

Conservação: preocupação menor. Exótica.

Nomes populares: capim-marmelada, milhã-branca.

Esta é a primeira vez que a espécie é referida para a RBMG-SP. Existe apenas um registro de sua ocorrência, realizado há 53 anos.

\section{Agradecimentos}

Aos colegas do Núcleo de Pesquisa Curadoria do Herbário SP, especialmente à Profa Dra. Maria Margarida da Rocha Fiuza de Melo e ao Prof. Dr. Sérgio Romaniuc Neto, pelas orientações durante o processo de configuração deste trabalho. À Profa Dra. Cintia Vieira da Silva, ao MSc. Victor Martins Gonçalez e à Msc. Mayara Pastore pelo estímulo e ajuda nas viagens de campo. Agradecimentos especiais são direcionados ao Prof. Dr. Fabio de Barros, à Dra. Mizuê Kirizawa, à Profa. Dra. Cintia Kameyama e ao Dr. Ricardo F. Garcia pelas orientações durante o período da qualificação. Ao Dr. Pedro Lage Viana e à Profa. Dra. Ana Paula Santos Gonçalves, membros da Banca Examinadora da Dissertação do primeiro Autor, e aos revisores anônimos por todas as imprescindíveis contribuições para o aprimoramento deste trabalho. Ao Instituto de Botânica e ao Programa de Pós-graduação em Biodiversidade Vegetal e Meio Ambiente. Aos amigos e Administradores da Reserva Biológica de Mogi-Guaçu por todo o suporte logístico. Ao CNPq pela Bolsa de Mestrado concedida ao primeiro Autor.

\section{Literatura citada}

Allem, A.C. \& Valls, J.F.M. 1987. Recursos forrageiros nativos do Pantanal Mato-Grossense. EMBRAPA, Brasília.

Arce, D. \& Sano, P.T. 2001a. Melinis. In: H.M. LonghiWagner, V. Bittrich, M.G.L. Wanderley \& G.J. Shepherd (eds.). Flora Fanerogâmica do Estado de São Paulo. Fapesp \& Hucitec, São Paulo, v.1, pp. 165-166.

Arce, D. \& Sano, P.T. 2001b. Rhynchelytrum. In: H.M. Longhi-Wagner, V. Bittrich, M.G.L. Wanderley \& G.J. Shepherd (eds.). Flora Fanerogâmica do Estado de São Paulo. Fapesp \& Hucitec, São Paulo, v.1, p. 232.

Boldrini, I.I. 2001. Pennisetum. In: H.M. Longhi-Wagner, V. Bittrich, M.G.L. Wanderley \& G.J. Shepherd (eds.). Flora Fanerogâmica do Estado de São Paulo. Fapesp \& Hucitec, São Paulo, v.1, pp. 228-231.

Canto-Dorow, T.S. 2014. Digitaria. In: Lista de Espécies da Flora do Brasil. Jardim Botânico do Rio de Janeiro. Disponível em: http://floradobrasil.jbrj.gov.br/jabot/ floradobrasil/FB13174 (acesso em 12-III-2014).

Canto-Dorow, T.S. \& Longhi-Wagner, H.M. 2001. Novidades taxonômicas em Digitaria Haller (Poaceae) e novas citações para o gênero no Brasil. Insula 30: 21-34.

Chase, A. 1929. The North American species of Paspalum. Contributions from the United States National Herbarium 28: 1-310.

Denham, S.S., Zuloaga, F.O. \& Morrone, O. 2002. Systematic revision and phylogeny of Paspalum subgenus Ceresia (Poaceae: Panicoideae: Paniceae). Annals of the Missouri Botanical Garden 89: 337-399.

Eiten, G. 1963. Habitat flora of Fazenda Campininha, São Paulo, Brazil. In: M.G. Ferri (coord.). Simpósio sobre o Cerrado. EDUSP, São Paulo, pp. 157-202. 
Filgueiras, T.S. 1984. O gênero Cenchrus no Brasil (Gramineae: Panicoideae). Acta Amazônica 14: 95-127.

Filgueiras, T.S. 2014a. Cenchrus. In: Lista de Espécies da Flora do Brasil. Jardim Botânico do Rio de Janeiro. Disponível em: http://floradobrasil.jbrj.gov.br/jabot/ floradobrasil/FB13073 (acesso em 12-III-2014).

Filgueiras, T.S. 2014b. Megathyrsus. In: Lista de Espécies da Flora do Brasil. Jardim Botânico do Rio de Janeiro. Disponível em: http://floradobrasil.jbrj.gov.br/jabot/ floradobrasil/FB25992 (acesso em 18-III-2014).

Filgueiras, T.S. 2014c. Pseudechinolaena. In: Lista de Espécies da Flora do Brasil. Jardim Botânico do Rio de Janeiro. Disponível em: http://floradobrasil.jbrj.gov.br/ jabot/floradobrasil/FB13541 (acesso em 12-III-2014).

Filgueiras, T.S. \& Oliveira, R.P. 2014a. Echinolaena. In: Lista de Espécies da Flora do Brasil. Jardim Botânico do Rio de Janeiro. Disponível em: http://floradobrasil. jbrj.gov.br/jabot/floradobrasil/FB13190 (acesso em 18-III-2014).

Filgueiras, T.S. \& Oliveira, R.P. 2014b. Hymenachne. In: Lista de Espécies da Flora do Brasil. Jardim Botânico do Rio de Janeiro. Disponível: http://floradobrasil. jbrj.gov.br/jabot/floradobrasil/FB13265 (acesso em 18-III-2014).

Filgueiras, T.S. \& Oliveira, R.P. 2014c. Lasiacis. In: Lista de Espécies da Flora do Brasil. Jardim Botânico do Rio de Janeiro. Disponível em: http://floradobrasil. jbrj.gov.br/jabot/floradobrasil/FB13295 (acesso em 12-III-2014).

Filgueiras, T.S. \& Rodrigues, R.S. 2014. Axonopus. In: Lista de Espécies da Flora do Brasil. Jardim Botânico do Rio de Janeiro. Disponível em: http://floradobrasil. jbrj.gov.br/jabot/floradobrasil/FB13032 (acesso em 18-III-2014).

Filgueiras, T.S. \& Shirasuna, R.T. 2009. Redescoberta de espécies presumivelmente extintas de Poaceae da Flora de São Paulo, Brasil. Hoehnea 36: 507-509.

Filgueiras, T.S., Oliveira, R.P., Sfair, J.C., Monteiro, N.P. \& Borges, R.A.X. 2013. Poaceae. In: G. Martinelli \& M.A. Moraes (orgs.). Livro Vermelho da Flora do Brasil. Instituto de Pesquisa Jardim Botânico do Rio de Janeiro, Rio de Janeiro, pp. 858-881.

Filgueiras, T.S., Longhi-Wagner, H.M., Viana, P.L., Zanin, A., Oliveira, R.C., Canto-Dorow, T.S., Shirasuna, R.T., Valls, J.F.M., Oliveira, R.P., Rodrigues, R.S., Santos-Gonçalves, A.P. \& Welker, C.A.D., Ferreira, F.M., Carvalho, M.L.S., Silva, A.S., Reis, P.A., Dórea, M.C., Silva, C. \& Mota, A.C. 2014a. Poaceae. In: Lista de Espécies da Flora do Brasil. Jardim Botânico do Rio de Janeiro. Disponível em: http://floradobrasil.jbrj.gov.br/jabot/floradobrasil/ FB193 (acesso em 12-III-2014).
Filgueiras, T.S., Oliveira, R.P. \& Dórea, M.C. 2014b. Oplismenus. Lista de Espécies da Flora do Brasil. Jardim Botânico do Rio de Janeiro. Disponível em: http:// floradobrasil.jbrj.gov.br/jabot/floradobrasil/FB13370 (acesso em 12-III-2014).

Filgueiras, T.S., Oliveira, R.P. \& Dórea, M.C. 2014c. Otachyrium. In: Lista de Espécies da Flora do Brasil. Jardim Botânico do Rio de Janeiro. Disponível em: http://floradobrasil.jbrj.gov.br/jabot/floradobrasil/ FB13372 (acesso em 18-III-2014).

Filgueiras, T.S., Oliveira, R.P. \& Dórea, M.C. 2014d. Parodiophyllochloa. In: Lista de Espécies da Flora do Brasil. Jardim Botânico do Rio de Janeiro. Disponível em: http://floradobrasil.jbrj.gov.br/jabot/floradobrasil/ FB13425 (acesso em 12-III-2014).

Filgueiras, T.S., Oliveira, R.P. \& Silva, C. 2014e. Ichnanthus. In: Lista de Espécies da Flora do Brasil. Jardim Botânico do Rio de Janeiro. Disponível em: http://floradobrasil.jbrj.gov.br/jabot/floradobrasil/ FB13273 (acesso em 18-III-2014).

Filgueiras, T.S., Reis, P.A. \& Oliveira, R.C. $2014 \mathrm{f}$. Melinis. In: Lista de Espécies da Flora do Brasil. Jardim Botânico do Rio de Janeiro. Disponível em: http:// floradobrasil.jbrj.gov.br/jabot/floradobrasil/FB25994 (acesso em 12-III-2014).

Filgueiras, T.S., Silva, A.S., Oliveira, R.C. 2014g. Anthaenantia. In: Lista de Espécies da Flora do Brasil. Jardim Botânico do Rio de Janeiro. Disponível em: http://floradobrasil.jbrj.gov.br/jabot/floradobrasil/ FB12974 (acesso em 18-III-2014).

Garcia-Santos, C.A. \& Sano, P.T. 2001. Echinolaena. In: H.M. Longhi-Wagner, V. Bittrich, M.G.L. Wanderley \& G.J. Shepherd (eds.). Flora Fanerogâmica do Estado de São Paulo. Fapesp \& Hucitec, São Paulo, v.1, pp. 152-153.

Genaro, D. 2011. Revisión del género Sacciolepis (Poaceae: Panicoideae: Paniceae) en su aspectos taxonómicos, histofoliares y filogenéticos. Tese de doutorado, Universidad de Buenos Aires, Buenos Aires.

Giraldo-Cañas, D. 2010. Novedades taxonómicas en Axonopus (Poaceae, Panicoideae, Paniceae) para Brasil. Rodriguésia 61: 137-142.

Giudice-Neto, J.D. (coord.) 2010. Plano de Manejo integrado das Unidades de Conservação: Reserva Biológica e Estação Ecológica, Mogi-Guaçu - SP, v. 1-2. Casa da Floresta/Secretaria do Meio Ambiente, Piracicaba/São Paulo.

GPWG (Grass Phylogeny Working Group). 2001. Phylogeny and subfamilial classification of the grasses (Poaceae). Annals of the Missouri Botanical Garden 88: 373-457.

GPWG (Grass Phylogeny Working Group). 2012. New grass phylogeny resolves deep evolutionary relationships and discovers C4 origins. New Phytologist 193: 304-312. 
IPNI (The International Plant Names Index). 2014. Disponível em: http://www.ipni.org (acesso em 18-III-2014).

IUCN (Standards and Petitions Subcommittee). 2014. Guidelines for Using the IUCN Red List Categories and Criteria. Version 11. Disponível em: http://www. iucnredlist.org/documents/RedListGuidelines.pdf (acesso em 18-III-2014).

Judziewicz, E.J. 1990. A New South American species of Sacciolepis (Poaceae: Panicoideae: Paniceae), with a summary of the genus in the New World. Systematic Botany 15: 415-420.

Longhi-Wagner, H.M., Bittrich, V., Wanderley, M.G.L. \& Shepherd, G.J. 2001. Poaceae. In: M.G.L. Wanderley, G.J. Shepherd \& A.M. Giulietti (coords.). Flora Fanerogâmica do Estado de São Paulo, v.1. Fapesp \& Hucitec, São Paulo.

Longhi-Wagner, H.M. (coord.), Valls, J.F.M., Oliveira, R.C., Zanin, A., Guglieri, A., Oliveira, R.P., Clark, L.G., Canto-Dorow, T.S., Boldrini, I., Filgueiras, T. \& Londoño, X. 2011. Poaceae. In: M.G.L. Wanderley, G.J. Shepherd, S.E. Martins, T.E.M.D. Estrada, R.P. Romanini, I. Koch, J.R. Pirani, T.S. Melhem, A.M.G. Harley, L.S. Kinoshita, M.A.G. Magenta, H.M. LonghiWagner, F. de Barros, L.G. Lohmann, M.C.E. Amaral, I. Cordeiro, S. Aragaki, R.S. Bianchini \& G.L. Esteves. Checklist das Spermatophyta do Estado de São Paulo, Brasil. Biota Neotropica 11: 342-354.

Mamede, M.C.H., Souza, V.C., Prado, J., Barros, F., Wanderley, M.G.L. \& Rando, J.G. (orgs.). 2007. Livro vermelho das espécies vegetais ameaçadas do Estado de São Paulo. Instituto de Botânica, São Paulo.

Mantovani, W. \& Martins, F.R. 1993. Florística do Cerrado na Reserva Biológica de Mogi Guaçu, SP. Acta Botanica Brasilica. 7: 33-60.

Morrone, O., Aagesen, L., Scataglini, M.A., Salariato, D.L., Denham, S.S., Chemisquy, M.A., Sede, S.M., Giussani, L.M., Kellogg, E.A. \& Zuloaga, F.O. 2012. Phylogeny of the Paniceae (Poaceae: Panicoideae): integrating plastid DNA sequences and morphology into a new classification. Cladistics 28: 333-356.

Oliveira, R.C. \& Valls, J.F.M. 2001. Paspalum. In: H.M. Longhi-Wagner, V. Bittrich, M.G.L. Wanderley \& G.J. Shepherd (eds.). Flora Fanerogâmica do Estado de São Paulo. Fapesp \& Hucitec, São Paulo, v.1, pp. 191-228.

Rodrigues, R.S. 2014a. Panicum. In: Lista de Espécies da Flora do Brasil. Jardim Botânico do Rio de Janeiro. Disponível em: http://floradobrasil.jbrj.gov.br/jabot/ floradobrasil/FB13374 (acesso em 12-III-2014).

Rodrigues, R.S. 2014b. Trichanthecium. In: Lista de Espécies da Flora do Brasil. Jardim Botânico do Rio de Janeiro. Disponível em: http://floradobrasil.jbrj.gov.br/ jabot/floradobrasil/FB129192 (acesso em 12-III-2014).
Rodrigues, R.S. \& Filgueiras, T.S. 2013a. Occurrence of Eriochloa distachya and Parodiophyllochloa penicillata (Poaceae) in São Paulo State, Brazil. Phytotaxa 138: 25-30.

Rodrigues, R.S. \& Filgueiras, T.S. 2013b. Redescoberta de Hymenachne pernambucensis (Poaceae: Paspaleae), espécie presumivelmente extinta no Estado de São Paulo. Hoehnea 40: 403-405.

Sánchez-Ken, J.G. \& Clark, L.G. 2010. Phylogeny and a new tribal classification of the Panicoideae s.l. (Poaceae) based on plastid and nuclear sequence data and structural data. American Journal of Botany 97: 1732-1748.

Sendulsky, T. 1978. Brachiaria: taxonomy of cultivated species in Brazil. Hoehnea 7: 99-139.

Sendulsky, T. \& Soderstrom, T.R. 1984. Revision of the South American genus Otachyrium (Poaceae: Panicoideae). Smithsonian Contributions to Botany 57: 1-24.

Shantz, H.L. 1954. The place of grasslands in the Earth's cover of vegetation. Ecology 35: 143-145.

Shirasuna, R.T. 2014a. Echinochloa. In: Lista de Espécies da Flora do Brasil. Jardim Botânico do Rio de Janeiro. Disponível em: http://floradobrasil.jbrj.gov.br/jabot/ floradobrasil/FB13185 (acesso em 12-III-2014).

Shirasuna, R.T. 2014b. Urochloa. In: Lista de Espécies da Flora do Brasil. Jardim Botânico do Rio de Janeiro. Disponível em: http://floradobrasil.jbrj.gov.br/jabot/ floradobrasil/FB20516 (acesso em 12-III-2014).

Shirasuna, R.T. \& Filgueiras, T.S. 2013. Bambus nativos (Poaceae, Bambusoideae) no Parque Estadual das Fontes do Ipiranga, São Paulo, SP, Brasil. Hoehnea 40: 315-359.

Shirasuna, R.T. \& Oliveira, R.P. 2014a. Sacciolepis. In: Lista de Espécies da Flora do Brasil. Jardim Botânico do Rio de Janeiro. Disponível em: http://floradobrasil. jbrj.gov.br/jabot/floradobrasil/FB13572 (acesso em 12-III-2014).

Shirasuna, R.T. \& Oliveira, R.P. 2014b. Steinchisma. In: Lista de Espécies da Flora do Brasil. Jardim Botânico do Rio de Janeiro. Disponível em: http://floradobrasil. jbrj.gov.br/jabot/floradobrasil/FB13628 (acesso em 18-III-2014).

Shirasuna, R.T. \& Rodrigues, R.S. 2014. Setaria. In: Lista de Espécies da Flora do Brasil. Jardim Botânico do Rio de Janeiro. Disponível em: http://floradobrasil. jbrj.gov.br/jabot/floradobrasil/FB13581 (acesso em 12-III-2014).

Shirasuna, R.T., Silva, A.S. \& Oliveira, R.C. 2014. Homolepis. In: Lista de Espécies da Flora do Brasil. Jardim Botânico do Rio de Janeiro. Disponível em: http://floradobrasil.jbrj.gov.br/jabot/floradobrasil/ FB13261 (acesso em 18-III-2014). 
Soreng, R.J., Davidse, G., Peterson, P.M., Zuloaga, F.O., Judziewicz, E.J., Filgueiras, T.S. \& Morrone, O. 2011 [onwards]. A world-wide phylogenetic classification of Poaceae (Gramineae). Disponível em: http://www. tropicos.org/projectwebportal.aspx?pagename $=$ Classi ficationNWG\&projectid=10 (acesso em 13-III-2014).

Thiers, B. 2014 [continuously updated]. Index Herbariorum: A global directory of public herbaria and associated staff. New York Botanical Garden's Virtual Herbarium. Disponível em: http://sweetgum.nybg.org/ih/ (acesso em 18-III-2014).

Tropicos.org. 2014. Missouri Botanical Garden. Disponível em: http://www.tropicos.org (acesso em 23-III-2014).

Valls, J.F.M. \& Oliveira, R.C. 2014. Paspalum. In: Lista de Espécies da Flora do Brasil. Jardim Botânico do Rio de Janeiro. Disponível em: http://floradobrasil.jbrj.gov.br/ jabot/floradobrasil/FB13432 (acesso em 18-III-2014).

Valls, J.F.M., Longhi-Wagner, H.M. \& Boldrini, I.I. 2001. Axonopus. In: H.M. Longhi-Wagner, V. Bittrich, M.G.L. Wanderley \& G.J. Shepherd (eds.). Flora Fanerogâmica do Estado de São Paulo. Fapesp \& Hucitec, São Paulo, v.1, pp. 129-141.

\section{Lista de exsicatas}

Cerati, T.M.: 142 (11.1; SP), 144 (12.2; SP), 146 (17.12; SP); Eiten, G.: 1483 (17.7; NY, SP), 1505 (9.3; NY, SP), 1536 (23.1; NY, SP), 1543 (17.23; NY, SP), 1549 (11.1; NY, SP), 1552 (4.3; NY, SP), 1559 (12.2; NY, SP), 1594 (4.3; NY, SP), 1614 (17.9; NY, SP), 1654 (17.4; NY, SP), 1669 (15.2; NY, SP), 1676 (17.22: NY, SP), 1750 (23.1; NY, SP), 1904 (12.2; NY, SP), 1940 (15.1; NY, SP), 1943 (23.1; SP), 1948 (2.4; SP), 1972 (21.1; NY, SP), 1973 (22.1; SP), 1974 (2.4; SP), 1975 (21.1; NY, SP), 1976 (17.19; SP), 1977 (23.1; NY, SP), 2116 (15.5; NY, SP), 2343 (23.1; NY, SP), 2577 (15.4.1; NY, SP), 2581 (2.6; SP), 2588 (9.1; SP), 2618 (9.3; SP), 2619 (17.15; NY, SP), 2658 (4.1; SP), 2659 (17.22; NY, SP), 2665 (21.1; SP), 2667 (22.1; SP), 2669 (17.22; NY, SP), 2670 (12.2; NY, SP), 2674 (17.20; NY, SP), 2676 (15.7; NY, SP); Feliciano, J.B.: 16 (12.2; SP); Gibbs, P.E.: 4270 (9.1; UEC); Handro, O.: 479 (15.6; SP); Klink, C.A.: 16767 (9.1; UEC), Kuhlmann, M.: 3939 (9.1; ICN, SP), 4189 (10.1; SP), 4192 (17.18; SP), 4194 (21.1; SP), 4195 (17.8; SP), 4196 (17.9; SP), 4252 (17.7; SP), 4253 (1.1; SP); Leitão-Filho, H.: 4300 (15.3; UEC), 12293 (9.1; UEC), Longhi-Wagner, H.M.: 3293 (17.24; SP, UEC), 3295a (15.2; SPF, UEC), 3295b (15.6; SP, SPF, UEC), 3296 (6.1; SP), 3297 (17.14; SP, UEC), 3298 (17.19; SP, UEC), 3299 (2.2; SP, SPF), 3301 (2.2; SP, SPF); Mantovani, W.: 180 (1.1; SP), 193 (15.4.2;
Viana, P.L. \& Filgueiras, T.S. 2008. Inventário e distribuição geográfica das gramíneas (Poaceae) na Cadeia do Espinhaço, Brasil. Megadiversidade 4: 71-88.

Zuloaga, F.O. 1994. Panicum. In: F.O. Zuloaga, O. Morrone, Z.E. Rúgulo de Agrasar, A.M. Anton, M.O. Arriaga \& A.M. Cialdella (orgs.). Gramineae V. Panicoideae - Paniceae. Flora del Paraguay 23. Missouri Botanical Garden Press, Saint Louis, pp. 211-320.

Zuloaga, F.O., Guglieri, A. \& Longhi-Wagner, H.M. 2001. Panicum. In: H.M. Longhi-Wagner, V. Bittrich, M.G.L. Wanderley \& G.J. Shepherd (eds.). Flora Fanerogâmica do Estado de São Paulo. Fapesp \& Hucitec, São Paulo, v.1, pp. 168-190.

Zuloaga, F.O., Morrone, O., Davidse, G., Filgueiras, T.S., Peterson, P.M., Soreng, R.J. \& Judziewicz, E. 2003. Catalogue of New World Grasses (Poaceae): III. Subfamilies Panicoideae, Aristidoideae, Arundinoideae, and Danthonioideae. Contributions from the United States National Herbarium 46: 1-662.

Zuloaga, F.O., Morrone, O., Vega, A.S. \& Giussani L.M. 1988. Revision y análisis cladísticos de Steinchisma (Poaceae: Panicoideae: Paniceae). Annals of the Missouri Botanical Garden 85: 631-656.

ICN, SP), 198 (17.7; SP), 209 (12.1; SP), 211 (12.1; SP), 248 (17.9; SP), 259 (12.2; SP), 296 (12.2; SP), 299 (12.1; SP), 318 (9.1; ICN, SP), 325 (15.3; SP), 333 (17.22; SP), 344 (21.1; SP), 364 (15.4.2; SP), 365 (15.5; SP), 367 (17.22; SP), 368 (2.6; CEN, SP), 374 (9.3; ICN, SP), 375 (2.5; SP), 387 (15.6; ICN, SP), 395 (12.2; SP), 397 (17.22; CEN, SP), 398 (15.2; SP), 399 (15.4.2; ICN, SP), 400 (15.4.2; SP), 447 (9.1; ICN, SP), 450 (9.1; ICN, SP), 471 (17.9; SP), 476 (2.6; CEN, SP), 477 (2.7; CEN, SP), 498 (15.4.2; SP), 499 (21.1; SP), 508 (15.6; ICN, SP), 514 (15.4.2; SP), 518 (2.6; SP), 522 (17.8; SP), 537 (2.5; SP), 556 (2.6; SP), 560 (12.2; SP), 563 (15.4.2; ICN, SP), 564 (17.22; CEN, SP), 584 (9.1; SP), 595 (17.9; SP), 603 (9.3; ICN, SP), 611 (2.6; SP), 613 (15.3; SP), 616 (2.7; SP), 623 (21.1; SP), 631 (17.20; CEN, SP), 686 (17.9; SP), 688 (2.1; SP), 709 (15.6; ICN, SP), 750 (2.5; SP), 758 (21.1; SP), 762 (2.7; SP), 770 (15.3; ICN, SP), 782 (2.6; SP), 797 (15.6; ICN, SP), 813 (15.3; ICN, SP), 816 (9.1; SP), 1033 (9.3; ICN, SP), 1046 (1.1; SP), 1093 (17.20; SP), 1156 (15.4.2; ICN, SP), 1230 (21.1; SP), 1290 (2.5; SP), 1296 (9.3; ICN, SP), 1317 (1.1; SP), 1335 (17.9; SP), 1367 (9.3; ICN, SP), 1397 (23.1; ICN, SP), 1399 (15.4.2; ICN, SP), 1426 (2.6; SP), 1439 (17.20. SP), 1457 (1.1; SP), 1567 (17.22; SP), 1583 (17.22; SP), 1590 (15.5; SP), 1660 (15.3; SP), 1661 (2.7; SP), 1686 (15.4.2; ICN, SP), 1698 (2.6; SP), 1700 (21.1; SP), 1711 (2.7; SP), 1712 (2.6; SP), 1716 (2.6; CEN, SP), 1728 (2.6; SP), 1769 (10.1; 
ICN, SP), 1782 (15.6; ICN, SP), 1820 (2.7; SP), 1825 (21.1; SP), 1827 (9.1; SP), 1860 (21.1; SP); Mattos, J.R.: 8294 (12.1; SP), 8321 (12.2; SP), 8458 (1.1; SP), 8492 (12.2; SP), 8500 (17.7; SP), 8537 (21.1; SP), 8550 (17.5; SP), 8552 (21.1; SP), 9647 (15.2; ICN, SP), 9666 (15.4.2; SP), 12224 (22.2; ICN, SP), 12228 (9.4; SP), 12255 (15.3; SP), 12256 (2.7; SP), 12292 (9.1; ICN, SP), 12486 (17.9; SP); Moraes, N.G.: 1 (2.6; SP), 6 (17.20; SP), 15 (7.1; SP), 17 (9.1; SP), 18 (12.2; SP), 20a (15.6; SP), 20b (15.6; SP), 22 (10.1; SP), 28 (2.6; SP), 37 (9.1; SP); Oliveira, C.M.: 15 (2.6; SP), 20 (15.4.2; ICN, SP), 60 (17.20; SP), 64 (2.5; SP), 75 (21.1; SP), 85 (2.6; CEN, SP), 89 (9.1; ICN, SP); Rodrigues, R.S.: 113 (23.1; SP), 114 (11.1; SP), 117 (15.6; SP), 122 (23.1; SP), 127 (9.2; SP), 128 (4.4; SP), 130 (24.1; SP), 138 (16.2; SP), 141 (17.13; SP), 142 (19.2; SP), 143(17.16; SP), 144 (19.1; SP), 145 (9.2; SP), 146 (15.6; SP), 147 (16.2; SP), 148 (9.4; SP) 149 (2.7; SP), 150 (6.1; SP), 153 (12.2; SP), 154 (9.1; SP), 155 (9.1; SP), 163 (15.7;
SP), 164 (4.4; SP), 177 (15.7; SP), 179 (7.1; SP), 180 (15.7; SP), 183 (20.1; SP), 185 (15.6; SP), 188 (9.2; SP), 189 (13.1; SP), 191 (17.16; SP), 195 (15.7; SP), 196 (15.6; SP), 198 (22.1; SP), 199 (23.1; SP), 202 (22.1; SP), 205 (11.1; SP), 209 (15.1; SP), 210 (17.2; SP), 212 (24.1; SP), 213 (17.24; SP), 214 (20.1; SP), 216a (16.2; SP); 216b (16.2; SP), 217 (17.9; SP), 222 (4.4; SP); 232 (13.1; SP), 233 (21.1; SP), 236 (17.4; SP), 241 (22.2; SP), 243 (4.4; SP), 244 (22.2; SP), 252 (22.2; SP), 254 (22.2; SP), 255 (16.3; SP), 257 (17.17; SP), 259 (2.2; SP), 268a (19.2; SP), 269 (2.2; SP); 277 (17.5; SP), 284 (9.1; SP), 292 (17.17; SP), 298 (11.1; SP), 299 (4.2; SP), s.n. (13.1; SP440801), s.n. (15.7; SP440804), s.n. (17.2; SP440805), s.n. (17.13; SP440806); Sendulsky, T.: 1119 (22.2; ICN, SP), 1126 (15.2; SP), 1127 (17.20; CEN, SP); Shirasuna, R.T.: 2915 (20.1; SP); Sugiyama, M.: 14 (17.22; CEN, SP), 39 (15.6; ICN, SP), 66 (9.1; ICN, SP), 76 (15.3; ICN, SP), 85 (15.3; ICN, SP), 103(21.1; SP), 109 (15.4.2; ICN, SP), 182 (15.3; ICN, SP), 184 (9.1; ICN, SP). 